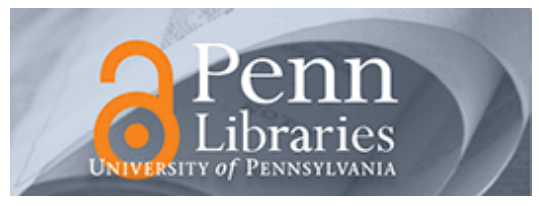

University of Pennsylvania

ScholarlyCommons

Finance Papers

Wharton Faculty Research

$9-2014$

\title{
Are Consumers Strategic? Structural Estimation from the Air- Travel Industry
}

Jun Li

Nelson Granados

Serguei Netessine

University of Pennsylvania

Follow this and additional works at: https://repository.upenn.edu/fnce_papers

Part of the Econometrics Commons, and the Finance and Financial Management Commons

\section{Recommended Citation}

Li, J., Granados, N., \& Netessine, S. (2014). Are Consumers Strategic? Structural Estimation from the AirTravel Industry. Management Science, 60 (9), 2114-2137. http://dx.doi.org/10.1287/mnsc.2013.1860

This paper is posted at ScholarlyCommons. https://repository.upenn.edu/fnce_papers/139

For more information, please contact repository@pobox.upenn.edu. 


\title{
Are Consumers Strategic? Structural Estimation from the Air-Travel Industry
}

\begin{abstract}
Consumers often consider delaying a purchase strategically, anticipating that prices might decrease. Combining two unique data sources from the air-travel industry (posted fare data and booking data), we use a structural model to estimate the fraction of strategic consumers in the population, assuming different levels of sophistication in consumers' perception of future prices: perfect foresight and weakand strong-form rational expectations. We find that $5.2 \%$ to $19.2 \%$ of the population is strategic across markets, measured by the first and third quartiles. Our intermarket analysis indicates that shorter trips with more attractive outside options are populated with more strategic consumers. Using a nonparametric approach, we further find that most strategic consumers arrive either at the beginning of the booking horizon or close to departure. Finally, our counterfactual analysis shows that, contrary to conventional wisdom, the presence of strategic consumers does not necessarily hurt revenues. Rather, the impact varies by market. Commitment to a nondecreasing pricing strategy is more likely to benefit business markets than leisure markets, or it could even hurt leisure markets. Intermarket analysis shows that city pairs with lower Internet penetration, higher average price, and shorter distances tend to benefit more from such commitment as well.
\end{abstract}

\section{Keywords}

econometrics, structural estimation, air travel, strategic customer behavior

\section{Disciplines}

Econometrics | Economics | Finance and Financial Management 


\title{
Are Consumers Strategic? Structural Estimation from the Air-Travel Industry
}

\author{
Jun Li \\ The Wharton School, lijun1@wharton.upenn.edu \\ Nelson Granados \\ Pepperdine University, nelson.granados@pepperdine.edu \\ Serguei Netessine \\ INSEAD, serguei.netessine@insead.edu
}

\begin{abstract}
Many consumers have learned to delay purchases, anticipating that prices might decrease. Such strategic or forward-looking behavior has attracted increasing attention from various disciplines, including operations management, marketing, and economics. However, there is currently no empirical evidence of the extent to which this strategic decision-making actually takes place. Combining two unique data sources from the air-travel industry (posted fares data and booking data), we use a structural model to estimate the fraction of strategic consumers in the population, assuming different levels of sophistication in consumers' perception of future prices: perfect foresight and rational expectations. We find that $4.9 \%$ to $44.9 \%$ of the population are strategic across markets, measured by the 5th and 95th percentiles. Using a non-parametric approach, we further find that most strategic consumers arrive either at the beginning of the booking horizon or close to departure. Finally, our counterfactual analysis shows that, contrary to conventional wisdom, the presence of strategic consumers does not necessarily hurt revenues. Rather, the impact varies by market - more likely to be negative on business markets, and positive on leisure markets. As a result, commitment to a non-decreasing pricing strategy benefits business markets but not leisure markets. Among markets benefiting from this pricing strategy, the median revenue improvement is $3.5 \%$, and the quantiles are $1.8 \%$ and $5.6 \%$.
\end{abstract}

\section{Motivation}

When was the last time you passed on an immediate purchase to wait for a sale? This can be a smart choice as inter-temporal price fluctuations are common across industries: fashion items are marked down several times towards the end of the season; storable goods are periodically put on sale; prices for high-tech gadgets with short life cycles dip soon after release; airlines, hotels, car rentals and theaters regularly revise prices or launch promotions. Of course, there are also consumers who do not strategize over the timing of purchase simply because they are not aware of the possibility that price decreases, have high waiting costs, or are not willing to forgo immediate gains in exchange for uncertain future gains. We will refer to strategic or forward-looking consumers as those who maximize long-run utility by strategically timing their purchases to obtain lower 
prices. We also refer to myopic and non-strategic consumers as those who maximize immediate utility and hence do not exhibit strategic behavior.

Studying strategic consumer behavior is important for several reasons. First, very little research to date provides direct and rigorous evidence of such behavior, relying instead on anecdotal accounts. Empirical evidence of strategic consumer behavior would not only enrich our knowledge of consumer behavior but also improve managerial decisions, such as pricing and inventory management. Second, most current demand forecasting models, including those used in airline revenue management systems, assume that consumer arrivals are exogenous and inter-temporally independent. However, correctly incorporating inter-temporal demand substitution may improve the accuracy of demand forecasting. Finally, revenue implications of strategic consumers could be significant. The common belief is that the presence of strategic consumers shifts demand from high to low prices, thus hurting revenues, but the extent of this effect is unclear: how to price and manage seat inventory in the presence of strategic consumers continues to puzzle industry professionals.

The air-travel industry is a particularly interesting test bed to study strategic consumer behavior. Unlike price fluctuations for seasonal or technological products, inter-temporal changes in airfares are much harder to predict. It is no longer surprising to learn that the person seated next to you on a plane paid much less for essentially the same seat. Revenue management, the practice of bucketing airfares into multiple classes and managing seat inventory dynamically, has revolutionized pricing (Talluri and van Ryzin 2005, Boyd 2007). Airlines constantly recompute protection levels and bid prices by taking into account the current number of available seats and latest demand forecasts, which results in constant opening, closing, and reopening of fare classes. Inventory managers can also override revenue management systems based on their expertise and local knowledge of demand; moreover, the pricing department revises fares periodically in response to changes in demand patterns, operating costs, and competitors' actions. Sometimes, pricing managers will launch temporal sales, which may trigger industry-wide price wars and further add to price swings. Therefore, even the same inventory class may not always be priced at the same level. All of this is likely to trigger fare shopping on the consumer side.

Despite this volatile nature of airfares, consumers are not helpless. Proliferation of web tools, e.g., major online travel agents (e.g., Expedia, Orbitz), fare aggregators (e.g., Kayak, Sidestep), and opaque channels (e.g., Hotwire, Priceline) have made it much easier for consumers to compare prices. Microsoft Bing/Travel (formerly Farecast) even makes a suggestion to "wait" or "buy" based on the probability of prices going up or down within the next seven booking days. Moreover, traditional offline agencies, which are often experienced and know the quirks of price movements, may help consumers obtain better deals in order to increase customer loyalty. Based on our spot checks of various travel-related online forums, some travelers have reported savings of $\$ 20$ to $\$ 150$ 
(or $7 \%$ to $33 \%$ ) by waiting for a better deal. Of course, consumers are not always that smart there are also cases in which travelers reported that they had to pay more since the price actually went up instead of going down.

In this paper, we merge two separate data sources to investigate just how strategic consumers actually are. First, we have collected information on posted rather than transacted prices. This is important because in order to investigate strategic consumer behavior we need to know not only the price paid, but also the prices that were potentially available. Second, many industries where one would suspect strategic consumer behavior have fragmented distribution channels. This normally limits access to sales information to a few retailers and makes it hard to obtain a complete picture of prices. In contrast, we are able to utilize booking information from Global Distribution Systems (GDSs), covering all bookings made through online and offline travel agents.

We use a simple yet flexible structural model to account for the dynamics caused by strategic consumers. Unlike most other empirical papers which incorporate forward-looking behaviors (e.g., Erdem and Keane 1996), our model does not impose the assumption of strategic consumer behavior a priori. We account for both static and dynamic price endogeneity, which cannot be easily addressed by reduced-form regressions. Moreover, our framework is flexible enough to incorporate many extensions with respect to consumer behavior, and it allows us to examine revenue implications through counterfactual analysis. Our structural estimation results suggest that $4.9 \%$ to $44.9 \%$ of travelers are strategic across different city-pair markets, measured by the 5th and 95th percentiles. This fraction varies by the time to departure in a non-linear fashion - most strategic consumers arrive either at the very beginning of the booking horizon or close to departure. Based on the estimation results, we draw important implications for airline revenue management strategies. Surprisingly, it turns out that the presence of strategic consumers does not always hurt revenues, since firms get incremental sales from strategic consumers who otherwise would not buy if myopic. Strategic behavior tends to decrease revenues in business markets but may increase revenues in leisure markets. As a result, commitment to a non-decreasing pricing scheme turns out to be desirable in business markets but not necessarily in leisure markets. Among markets benefiting from this pricing strategy, the median revenue improvement is $3.5 \%$, and the lower and the upper quantiles are $1.8 \%$ and $5.6 \%$, comparable to revenue improvements commonly reported (see Talluri and van Ryzin 2005).

\section{Literature Review}

It is a common practice to assume an exogenous demand process in traditional revenue management research (e.g., Belobaba 1989, Gallego and van Ryzin 1994). Recently, however, there is a growing interest in studying operational decisions in the presence of strategic consumers (see Shen and 
Su 2007, Netessine and Tang 2009 for a review). Several papers have investigated the impact of strategic consumers on firms' strategies such as inventory procurement (Cachon and Swinney 2009), capacity rationing (Liu and van Ryzin 2008), and revenue management (Jerath et al. 2010), to name a few. One of the key findings from the modeling literature is that strategic consumers may exert a negative impact on firms' revenue: Anderson and Wilson (2003) find a 7\% revenue loss; Aviv and Pazgal (2008) find a 20\% revenue loss; Levin et al. (2009) find a 1\% to $7 \%$ revenue loss. Nevertheless, other papers predict that strategic consumers can have either adverse or positive effects on seller revenue (Su 2007, Cho et al. 2008).

Despite the burgeoning interests from the modeling perspective, empirical evidence of strategic consumers is scarce and scattered in three streams of related literature. First, in the realm of revenue management, a few recent empirical papers study consumers' choices among multiple products (Vulcano et al. 2010, Newman et al. 2010) but without accounting for inter-temporal choice behavior. Second, in marketing and economics there is a stream of literature that incorporates forward-looking consumer behavior, starting with Erdem and Keane (1996). More recent papers include Hendel and Nevo (2006) and Nair (2007), to name a few. However, most of these papers build on the premise that consumers are forward-looking a priori, and the research objective is to uncover consumer preferences rather than investigate how strategic consumers are. Third, behavioral economists have long been looking at inter-temporal choices and time-discounting. A closely related recent work by Osadchiy and Bendoly (2010) reports that $38 \%$ of the subjects behave rationally in laboratory experiments by strategically timing their purchases.

To provide evidence of strategic consumer behavior, there are at least two potential estimation approaches. The first approach is to estimate a discount factor as a continuous measure of consumer patience (e.g., Levin et al. 2009). There are two difficulties associated with this approach identification and computational complexity. In the aforementioned empirical studies of dynamic models, utility functions cannot be identified (non-parametrically) when the discount factor is not fixed (see Rust 1994, Magnac and Thesmar 2002). Although parametric restrictions will allow utility functions to be identified jointly with the discount factor, the computational complexity usually makes it undesirable to do so. As a result, the common practice is to fix the value of the discount factor and conduct sensitivity analysis on this value, if necessary. The other approach is to segment the market into discrete consumer types - myopic and strategic (e.g.,Su 2007), and to estimate the fraction of strategic consumers. A similar idea has been applied in the latent class models in the marketing literature (Dillon and Kumar 1994). This approach greatly streamlines the estimation. Meanwhile, it is analogous to market segmentation and can be easily explained to and understood by industry professionals, so we adopt this approach. 
Given the difficulty in identifying strategic behavior and the lack of appropriate field data, so far very little research provides direct evidence of strategic consumers. To the best of our knowledge, there are only two studies parallel to this paper. Chevalier and Goolsbee (2009) test whether textbook users are forward-looking by anticipating book revisions. They take the discount factor approach since the structure of the value function is much simpler in this setting. Another example is an unpublished paper by Hendel and Nevo (2011), who propose a demand anticipation model to account for consumer stockpiling behavior during temporary sales and obtain an estimate of the fraction of stockpilers. Our work is related to theirs as we also look at aggregate data and the model bears similar structure, but we differ in three aspects. First, the research objective is different. We start out with the purpose of documenting whether consumers are strategic or not, while their focus is the inter-temporal price discrimination as a mechanism of market segmentation. As a result, we ask different questions oriented towards strategic consumers: What factors affect the fraction of strategic consumers? What if more consumers become strategic? What pricing strategies may airlines adopt in response to strategic consumers? Second, prices are more volatile and harder to predict in the airline industry, and hence the existence of strategic consumer behavior is less obvious. Third, demand is relatively stable over time in their setting, and therefore price endogeneity is less of a concern. However, in our setting, due to the practice of revenue management, price endogeneity is an important issue that needs to be properly addressed.

Finally, significant amount of price dispersion (Clemons et al. 2002, Chellapp et al. 2011) and inter-temporal fluctuation (Etzioni et al. 2003, Mantin and Gillen 2011) has been documented in the air-travel industry, which likely gives rise to the existence of strategic consumers.

To sum up, our study contributes to several streams of literature. Assembling field data to uncover inter-temporal choices is a significant challenge due to the level of detail and multiple data sources required. Our data is unique in this sense because it provides a detailed dynamic view of daily available prices and realized demand. Moreover, the structural model we propose is simple yet flexible, and at the same time it is consistent with aforementioned modeling literature, so our approach can be used to calibrate subsequent models.

\section{Data}

We use two main datasets with millions of records that provide information on airfares and bookings, respectively. First, fares are web-crawled from the major online travel agencies: Expedia, Travelocity, Orbitz, and Priceline. The dataset contains posted fares over a three-month booking period before each day of departure for each city-pair market. The departure dates are a random set of seven weeks including both peak and off-peak weeks in the spring travel season of 2005. On each booking day, we extract the three lowest round-trip (with seven-day length of stay) fares from 
each online travel agency for each particular market and departure date. A fare record contains: booking date, departure date, origin and destination airports, carrier, inventory class, fare types, fare amounts, booking agency, and other details of the itinerary. We have also validated the webcrawled fare information by matching it with transaction prices obtained from a corporate sponsor in the same time period (matched with a correlation of 0.860). Second, booking data from the Marketing Information Data Transfer (MIDT) is obtained from an airline corporate sponsor. It contains U.S. point-of-sale reservations made in all major GDSs. GDSs distribute a large proportion of airline tickets via offline and online travel agents, accounting for $50 \%$ to $70 \%$ of all sales in the U.S., so we are able to ensure that sales information is available for most distribution channels. Markets are selected based on the largest passenger volume for the airline sponsor while ensuring wide geographic coverage of cities with large populations. These markets represent about $80 \%$ of market coverage for the airline. The dataset contains the following information on the outbound leg of all economy-class reservations: reservation date, departure date, origin and destination airports, carrier, inventory class, the booking agency, and number of passengers. The data provide a relatively comprehensive view of air-ticket reservations including their time stamps. Note that MIDT does not contain price information, and we merge it with the web-crawled price information. Whenever needed, we supplement this data using other publicly available sources, such as the DB1B 10\% air ticket sample from the Department of Transportation and population and income data from the Bureau of Economic Analysis.

In sum, there are 5.9 million booking records and 4.5 million fare records. We merge the two datasets according to markets, departure dates and booking dates. Thus, the combined dataset provides a nearly complete picture of daily ticket sales and daily lowest fares for 111 city-pair markets (84 domestic), 45 departure dates, and three-month booking period for each departure date. In this paper we focus on inter-temporal decisions and aggregate the data across airlines. We could explicitly consider substitution among different flights and carriers on the demand side and airline competition on the supply side. We do not possess data to fully implement this approach since we would need price histories associated with all outbound and inbound flight combinations of all airlines. Additionally, complexity of the model increases manyfold because one has to model and compute the competitive equilibrium among airlines in addition to modeling consumer expectations. We leave this for future research. Based on our preliminary analysis, however, we believe that modeling these aspects is secondary since our focus is on the inter-temporal substitution: we did attempt to control for the competition level in a crude way but found no significant effects, as we demonstrate later.

Even though we have taken great effort to assemble this massive database, note that this data is aggregate in that we observe only the daily purchases and available prices, not individual search 
behavior. However, in most circumstances, firms have access only to aggregate data such as we have here, in which case structural estimations are appropriate to infer strategic consumer behavior. We further aggregate the data by booking week for the following reasons: First, this aggregation level is consistent with industry practices and with related papers (Mantin and Gillen 2011, Hendel and Nevo 2011, Granados et al. 2011): a common practice to construct a fare class is to require 21-/14-/7-day advance purchase. As a result, price varies more from week to week than from day to day as we will demonstrate. Second, one would expect that even myopic consumers may take a few days before making a purchase decision, and even the most strategic consumers cannot wait indefinitely. Letting consumers make purchase decisions at the weekly level allows us to account for air-travel planning horizons of both myopic and strategic consumers to a certain extent. Finally, for reasons to be explained later, aggregation at a lower level would make estimation prohibitively complex computationally.

We note significant amount of price variation from the data. The overall standard deviation of prices is about $80 \%$ of the mean, as shown in Table 1 . To further investigate the inter-temporal component of the price variation, we summarize frequencies of price trends in Table 2. On average, the weekly fare decreases in the subsequent week with $39.5 \%$ probability, increases with $51.2 \%$ probability, and remains constant with $9.3 \%$ probability. In comparison, most often $(47.2 \%$ of the time) the daily fare stays unchanged. This probability varies significantly by market, departure date and booking week. This persistent inter-temporal variation underscores the uncertainty in prices faced by air-travel consumers, and also the potential opportunities for consumers to strategize on the timing of purchase.

\section{Preliminary Results using Reduced-Form Regressions}

Before formulating the structural model, we first look at preliminary results from reduced-form regressions, which highlight the potential endogeneity problems and lead us to the structural approach. In the absence of strategic consumers, demand $d_{t}$ in period $t$ is correlated with the price of that period $p_{t}$, but not with prices of past or future periods, everything else being properly controlled for. However, when some consumers strategically postpone their purchase decisions in anticipation of a price decrease, demand will be correlated with past and future prices. The lower the future prices or expected future prices, the more likely consumers are willing to delay their purchases. To test this, we estimate weekly demand using the following three models: 1) a basic model that accounts only for the price of the current week, 2) a model that accounts for realized future and past prices, 3) a model that accounts for expected prices. To show the primary effects, we consider prices only one period (i.e., one week) ahead:

$$
d_{t}=\alpha+\beta_{0} p_{t}+X \gamma+\varepsilon_{t}
$$




$$
\begin{aligned}
& d_{t}=\alpha+\beta_{0} p_{t}+\beta_{1} p_{t+1}+\beta_{2} p_{t-1}+X \gamma+\varepsilon_{t} \\
& d_{t}=\alpha+\beta_{0} p_{t}+\beta_{1} \hat{p}_{t+1}+\beta_{2} p_{t-1}+\beta_{3} \hat{p}_{t}+X \gamma+\varepsilon_{t}
\end{aligned}
$$

where the $X$ includes covariates such as polynomials of booking time and market departure date characteristics; see Table 3 for a description of these variables. Controlling for the realized future and past prices, Model 2 corresponds to the case in which strategic consumers have perfect knowledge about future prices. We expect $\beta_{1}$ and $\beta_{2}$ to be positive if there is inter-temporal substitution. However, consumers most likely do not have perfect knowledge of future prices, but rather make predictions of future prices based on historical prices and other information available. We control for the expected prices $\hat{p}_{t+1}$ and $\hat{p}_{t}$ in Model 3. Expected prices are obtained using four period lags of prices and other market covariates, which together explain up to $80 \%$ to $90 \%$ of the price variations. Strategic consumers who arrive at time $t-1$ will base their timing of purchase on price $p_{t-1}$ and the expected price $\hat{p}_{t}$. The coefficient $\beta_{1}, \beta_{2}$ in Model 3 should have the same sign as in Model 2, while the coefficient $\beta_{3}$ of $\hat{p}_{t}$ should have a sign opposite to $\beta_{2}$.

We run regressions on a sample market and present the results in Table 4. All signs are as expected except for that of the lagged price in Model 2, largely supporting our belief about the presence of strategic consumers. The results tell us how sensitive the current demand is to prices in adjacent time periods. Although this simple approach is indicative of the presence of strategic consumers, it suffers from several drawbacks. First is the price endogeneity commonly seen in static settings. The current price may be correlated with the current demand shock as firms usually have better knowledge of demand shocks than we do as econometricians, leading to positively biased price sensitivities. Second, the dynamics add an additional layer to price endogeneity. For example, in Model 2, the positive correlation between demand $d_{t}$ and future price $p_{t+1}$ can be explained either as strategic consumers waiting for prices to drop or as prices drop as a result of previously realized low demand, again biasing the price sensitivity positively. Using expected prices instead of realized prices may alleviate but not fully resolve this problem. The expected future price can still be correlated with demand shocks through the current price, which again introduces positive bias in price sensitivities. In fact, we do find many insignificant price coefficients for many markets. Since all price variables are endogenous, we would need multiple Instrument Variables (IVs), and finding IVs in this setting is not trivial because they would need to vary across the booking periods. Cost-based supply shifters (e.g., fuel prices and labor costs) are not useful because weekly prices do not respond to these cost factors in the short run. Other IVs used in airline studies, such as distance and demographics (Borenstein and Rose 1994, Granados et al. 2011) are not applicable either since they do not vary over the booking period. In addition to the endogeneity problem, it is also not clear how to explain the estimated coefficients (e.g., $\beta_{1}, \beta_{3}$ ): although one would get 
a sense of how sensitive demand is to adjacent prices, it is hard to get a sense of how strategic consumers are from these estimates, especially if we want to compare them across markets. In sum, although reduced-form regressions seem to provide some evidence of varying prices and strategic consumer behavior, these simple models cannot properly address multiple econometric issues. We turn next to the structural modeling approach.

\section{The Structural Model}

\subsection{The Demand Model}

We first consider the decision of a consumer who desires to travel in a particular city-pair market on a particular departure date. We assume that both the market and the day of departure are given exogenously. To focus on the inter-temporal substitution, we further ignore substitution between nearby airports and among adjacent departure dates. In our model, needs for travel arise exogenously. A consumer arriving at the booking time $t$ can be either strategic (with probability $\theta$ ) or myopic (with probability $1-\theta$ ). Our goal is to obtain an estimate of the fraction of strategic consumers (i.e., $\theta$ ) in the population.

Myopic consumers are those who arrive at $t$ and immediately make a purchase-or-not decision. If a myopic consumer decides not to buy at time $t$, he will never come back. Strategic consumers are those who arrive at $t$ but may decide to postpone their purchase and come back later. For computational reasons, we make a conservative assumption that strategic consumers wait for at most one period of time ${ }^{1}$. Should she decide to wait, she will come back later and decide whether or not to purchase the ticket. The waiting decision of a strategic consumer depends on her expectation of future prices, which we discuss later. Consumers in our model are heterogeneous along the following three dimensions: 1) time of arrival (e.g., Su 2007, Aviv and Pazgal 2008); 2) strategic or myopic (e.g., Su 2007, Cachon and Swinney 2009); and 3) valuation of the products (e.g., Levin et al. 2009). Valuation does not affect waiting decisions in our model as we discuss shortly. Furthermore, we will allow for different price sensitivities between strategic and myopic consumers to incorporate heterogeneity in valuation distributions among them.

Knowing the consumers' problem, we model the aggregate demand observed in each booking period. The aggregate demand $d_{m t}$ on a city-pair market and departure date dyad $m$ and at booking time $t$ is composed of three subgroups: 1) myopic consumers who arrive and decide to buy at time $t$; 2) strategic consumers who arrive and decide to buy at time $t$; 3 ) strategic consumers who arrive at time $t-1$ but wait for one more period and finally decide to buy at time $t$. Specifically,

$$
d_{m t}=\underbrace{(1-\theta) q\left(p_{m t}, X_{m}, t\right)}_{\text {myopic who purchase at } t}+\underbrace{\theta\left(1-z_{m t}\right) q\left(p_{m t}, X_{m}, t\right)}_{\text {strategic who arrive and purchase at } t}+\underbrace{\theta z_{m, t-1} q\left(p_{m t}, X_{m}, t-1\right)}_{\text {strategic who arrive at } t-1 \text { and purchase at } t}
$$

\footnotetext{
${ }^{1}$ Estimation with two or more waiting periods is extremely expensive computationally. We tried allowing for twoperiod waiting under simpler expectation assumptions, perfect foresight and weak-form rational expectation. The estimated percentage is comparable while slightly smaller. However, the amount of strategic waiting, i.e., (amount of time waiting) $*$ (number of people waiting), is almost the same.
} 
where $z_{m t}$ equals 1 if a strategic consumer decides to wait at time $t$, and 0 otherwise, and $q(\cdot)$ is the baseline demand that one would observe if all consumers were myopic. Note that the model itself does not impose the assumption of strategic behavior: only if $\theta$ is significantly different from zero will we have the evidence of strategic behavior. The baseline demand is a function of price $p_{m t}$, market and departure-date characteristics $X_{m}$, and the time of booking $t$. Note that the effective price for those consumers who arrive in the last period $t-1$ but wait until $t$ is the current price $p_{m t}$ rather than the last period's price $p_{m, t-1}$. That is, strategic consumers who decide to wait are not obligated to buy when they come back, and the decision will depend on the new price they see. Thus, the demand contribution from those who arrive in the previous period is $q\left(p_{m t}, X_{m}, t-1\right)$ rather than $q\left(p_{m, t-1}, X_{m}, t-1\right)$. In the following subsections, we discuss in detail the modeling alternatives, assumptions, and potential extensions of each input of this model.

5.1.1. Baseline Demand Functional Form. The baseline demand $q\left(p_{m t}, X_{m}, t\right)$ represents the potential demand we will observe if all consumers are myopic. A common way to model demand is the additive linear demand model: $q\left(p_{m t}, X_{m}, t\right)=\alpha-\beta p_{m t}+f(t)+X_{m} \delta+\varepsilon_{m t}$, where $f(t)$ captures the time trend approximated, for instance, by a polynomial function of booking time $t$, and $\varepsilon_{m t}$ is the demand shock. The main results of this paper will be based on the linear model, but we also present results with the nonlinear exponential demand model with multiplicative errors: $q\left(p_{m t}, X_{m}, t\right)=\exp \left(\alpha-\beta p_{m t}+f(t)+X_{m} \delta+\varepsilon_{m t}\right)$.

Endogeneity of Price and Structure of Demand Shocks. Even though we control for market-departure-date characteristics, prices may still be endogenous in this setting. First, pricing managers who monitor the demand and prices have better knowledge about the local demand than we do as econometricians. For example, when there is a special event, such as a conference or a convention, managers might adjust prices for that departure date and city accordingly. Second, pricing managers adjust prices based on previously realized demand shocks, and if demand shocks are auto-correlated, prices will be correlated with contemporaneous demand shocks as well. These particular features of the air-travel industry make price endogeneity a more prominent issue than in many other industries, such as the one studied in Hendel and Nevo (2011) where demand is more stable over time. Failure to address these endogeneity issues will result in biased estimates of price sensitivity, and hence the estimates of other parameters of the model such as the fraction of strategic consumers. The direction of this bias can go both ways. If price endogeneity is not properly accounted for, as usual, price sensitivities will be underestimated. During price drops, a part of the incremental demand caused by the price sensitivity of myopic consumers will be attributed to strategic consumers, so the fraction of strategic consumers will be overestimated. During price surges, however, the observed decrease in demand is smaller with strategic consumers than without 
them. Since the potential decrease in demand without strategic consumers is underestimated, the part attributed to the strategic consumers, that is, potential decrease minus observed decrease, will be underestimated. The overall effect is ambiguous. To address the endogeneity, we allow for the following structure of demand shocks:

$$
\begin{aligned}
& \varepsilon_{m t}=\mu_{m}+\epsilon_{m t}, \\
& \epsilon_{m t}=\rho \epsilon_{m, t-1}+\nu_{m t},
\end{aligned}
$$

where the demand shock $\varepsilon_{m t}$ is decomposed to a market-departure-date specific shock, $\mu_{m}$, and a serially correlated shock governed by $\mathrm{AR}(1)$ process, $\epsilon_{m t}$. Price $p_{t}$ is allowed to be correlated with the demand shock $\varepsilon_{m t}$ through correlation with $\mu_{m}$ and $\epsilon_{m, t-1}$. The remaining part of the demand shock, $\nu_{m t}$, is a pure noise, i.i.d across markets, departure dates and booking periods, and uncorrelated with other observables, including prices.

Heterogeneity in Price Sensitivities between Myopic and Strategic Consumers. One might expect strategic consumers to be more sensitive to prices than non-strategic consumers. To allow for this possibility, let $\beta_{n}$ and $\beta_{s}$ denote the price sensitivities of non-strategic and strategic consumers, respectively. The demand can be written as follows,

$$
\begin{aligned}
d_{m t} & =(1-\theta) q_{n}\left(p_{m t}, X_{m}, t\right)+\theta\left(1-z_{m t}\right) q_{s}\left(p_{m t}, X_{m}, t\right)+\theta z_{m, t-1} q_{s}\left(p_{m t}, X_{m}, t-1\right), \\
q_{n}\left(p_{m t}, X_{m}, t\right) & =\alpha-\beta_{n} p_{m t}+f(t)+X_{m} \delta+\varepsilon_{m t}, \\
q_{s}\left(p_{m t}, X_{m}, t\right) & =\alpha-\beta_{s} p_{m t}+f(t)+X_{m} \delta+\varepsilon_{m t} .
\end{aligned}
$$

Now we need to be careful about the interpretation of the fraction $\theta$. In the previous case where strategic and non-strategic consumers have the same price sensitivities, the fraction of strategic consumers is constant regardless of prices. However, the observed fraction will change with prices if different price sensitivities are permitted. The higher the price, the fewer strategic consumers we expect to observe. Thus, the fraction $\theta$ represents the relative scale of strategic consumers at price zero. We define the observed fraction of strategic consumer $\theta_{o b s, t}$ at time $t$ as $\theta_{o b s, t}=$ $q_{s}\left(p_{m t}, X_{m}, t\right) / q_{n}\left(p_{m t}, X_{m}, t\right)$.

5.1.2. Consumer Expectations. Strategic consumers' waiting decision is based on their beliefs about future prices. Note that price levels also manifest the risk of stock-out thanks to the practice of revenue management. Bid prices, as approximated by the lowest prices in our model, reflect the level of remaining seat inventory or the probability of stock-out at different booking occasions. We model consumers' waiting decision under three different circumstances with a decreasing level of consumer sophistication: perfect foresight, strong-form rational expectations and weak-form rational expectations. Under perfect foresight consumers predict future prices perfectly. 
Under rational expectations, consumers cannot predict the exact price individually, yet as a group they predict the future price distribution correctly. The distinction between strong form and weak form is that, under the strong-form, consumers consider airlines' pricing strategy when forming the expectation, while under the weak-form, the expectation is based on historical information only.

Perfect Foresight. At time $t$, strategic consumers know the exact future price $p_{m, t+1}$. Though unrealistic, this model can be used as a benchmark. Consider a consumer with utility of traveling denoted by $\phi$. She will decide to wait if $\phi-p_{m, t+1}>\phi-p_{m t}$, or $p_{m, t+1}<p_{m t}$, that is, if price drops in the next period. Note that time discounting is negligible in this setting since we are looking at relatively short time periods such as days or weeks. Moreover, utility of air-travel does not depend on the time of purchase: the product is always consumed on the day of departure. As a result, a consumer's purchase-or-wait decision is not dependent on the value of the product $\phi$. In this model we do not consider costs of waiting (e.g., costs associated with obtaining a price quote again in the future) or benefits of waiting (e.g., flexibilities associated with keeping the schedule open and committing at a later time). Moreover, when a consumer anticipates future prices perfectly, risk attitude will not be a determinant of the purchase-or-wait decision.

Weak-Form Rational Expectation. A strategic consumer $i$ makes a prediction of the future price $p_{m, t+1}$ at time $t$ based on information available to her at time $t$, i.e., $I_{m t}$ and a personal shock, i.e., $o_{i m t}, \tilde{p}_{i, m, t+1}=E\left[p_{m, t+1} \mid I_{m t}\right]+o_{i, m t}$, where $E\left[p_{m, t+1} \mid I_{m t}\right]$ is the expectation of future prices given information set $I_{m t}$. Information set $I_{m t}$ includes, for instance, historical prices, price volatility, and market departure date characteristics. Under the rational expectation assumption, the distribution of consumer belief $\tilde{p}_{i, m, t+1}$ is the same as that of the true conditional distribution of future price $p_{m, t+1} \mid I_{m t}$. Therefore, the probability that strategic consumers wait will be the same as $\operatorname{Pr}\left(p_{m, t+1}<p_{m t} \mid I_{m t}\right)$, which can be estimated using a Logit or Probit model.

Strong-Form Rational Expectation. Consumers now consider airlines' pricing strategy when forming expectation of future prices. Consider the following game played by the airline and the consumers. Stage 1: at the beginning of time $t$, baseline demand shock $\nu_{m t}$ is realized, and consumers arrive and see the $p_{m t}$. Myopic consumers make their purchase based on $p_{m t}$. Each strategic consumer forms her own prediction of future price and makes the purchase-or-wait decision. Total demand $d_{m t}$ is thus realized. Stage 2 : at the beginning of time $t+1$, a supply shock denoted by $\omega_{m, t+1}$ is realized and airlines make a decision on price $p_{m, t+1}$ based on the previous demands $d_{m k}, k=1,2, \ldots, t$, the observed supply shock $\omega_{m, t+1}$ and other inputs.

In the rational expectations equilibrium, strategic consumers collectively anticipate the true price distribution. Consumers do not necessarily need to know the exact demand shock $\nu_{m t}$. As long as it is realized, this information will not be wasted in an efficient market. The only source of variation for the price $p_{m, t+1}$ at the time when consumers form expectations is the unrealized supply shock. 
With this assumption, the equilibrium belief of future price distribution and probability of waiting can be found through estimating the supply model, which we describe in the next section.

Under either weak-form or strong-form rational expectation, once we obtain the probability of strategic consumers waiting $P r_{m t}$, we can replace $z_{m t}$ with $P r_{m t}$ in Equation 4 . We note that the rational expectations model is likely to provide higher estimates of the fraction of strategic consumers than the perfect foresight model. The reason is that, under the perfect foresight, every strategic consumer anticipates price drops correctly and waits. Under the rational expectations, only a portion of strategic consumers correctly anticipate price drops. Thus, the same amount of demand shifting observed in the data caused by strategic waiting corresponds to more underlying strategic consumers under the rational expectations assumption.

5.1.3. Fraction of Strategic Consumers. So far we have assumed the fraction of strategic consumers to be time-independent. However, strategic consumers may be more likely to arrive at certain stages over the booking horizon. We estimate a vector of fractions for the entire booking horizon non-parametrically, $\tilde{\theta}=\left[\theta_{1}, \theta_{2}, \ldots, \theta_{T-1}\right]$, where $\theta_{t}$ represents the fraction of strategic consumers arriving at the booking time $t$, and $T$ is the final booking period. Note that no strategic consumers arrive in the last period before departure, i.e., $\theta_{T}=0$, which is also true in the case of constant fraction.

\subsection{The Supply Model}

Recall that one reason to specify the supply model (or pricing strategy) is to estimate the demand model under the strong-form rational expectations. Another reason is that we need to know the firm's strategy in order to compute new equilibrium in the counterfactual analysis as we change certain parameters. Ideally, the most desired supply model would mimic the exact network-based dynamic inventory control algorithms and demand forecasting strategies used in the airline industry, and take into account the effect of competition. Such a dynamic game is far too complex to be amenable both analytically and computationally within the scope of this paper. Moreover, this approach would invoke an assumption on firms' current conduct - that they are profit maximizers and already make the optimal decisions. This may not be the case (e.g., we know airlines do not currently take strategic consumers into account), and, more important, this assumption would make our pricing recommendations redundant. Instead, we take an empirical approach to approximate the firms' current equilibrium pricing strategy, as many other structural models do (e.g., Nair 2007). Note that short-term price fluctuations in the airline industry are not based on costs, as fixed costs are sunk and marginal costs are minimal. The key determinants of prices are the remaining seat inventory and demand forecasts (see Gallego and van Ryzin 1994). When restricted to one particular market, we can account for the remaining inventory level using the cumulative 
demand since the total capacity is largely fixed in the short term. We therefore model the price as a function of previous prices and demands, market and departure date characteristics, and supply shocks. We find that lag-1 price, initial price $p_{m 0}$, and cumulative demand up to time $t$ together with other controls are able to explain nearly $90 \%$ of the price variations for most markets. We therefore choose the following parsimonious model on the supply side:

$$
p_{m, t+1}=\gamma_{p} p_{m t}+\gamma_{d} \text { cum_demand }{ }_{m t}+\gamma_{0} p_{m 0}+X_{m, t+1} \gamma+\omega_{m, t+1}, \omega_{m, t+1} \sim N\left(0, \sigma_{m, t+1}\right),
$$

$\omega_{m, t+1}$ is a random supply shock, which we assume to be uncorrelated with the demand shock. Since the fixed component $\left(\mu_{m t}\right)$ and the autocorrelated component $\left(\rho \epsilon_{m t}\right)$ of the demand shock are accounted for by lag-1 price, cumulative demand, and initial price. The remaining part of time $t+1$ demand shock $\left(\nu_{m, t+1}\right)$ can be assumed to be uncorrelated with $\omega_{m, t+1}$. We do not find evidence of serial correlation in the residuals after controlling for the lag-1 price. However, we do find evidence of heteroscedasticity in the residuals over booking time, so we allow the variation of the supply shock $\left(\sigma_{m t}\right)$ to change with booking time.

It is important to note at this point how the structural model outperforms the reduced-form regressions in addressing the econometric issues previously discussed. First, the mechanism by which expected prices affect current and future demands is explicitly specified in the structural model, rather than merely through correlations $\left(\beta_{1}, \beta_{3}\right)$ in the reduced-form regressions. More important, the error generating process is explicitly specified as well. As the demand inlcudes both strategic and myopic consumers, the demand shock is composed of shocks to both groups as well. The shock first affects the arrival of both strategic and myopic consumers, and then translates into the current and future demands dependent on the strategic behaviors. In the reduced-form regression, we have only one blended error term. Even if one can arbitrarily apply techniques to control for fixed effects and serial correlation in reduced-form regressions, it makes more sense to specify the underlying error generating process.

\section{Identification and Estimation 6.1. Identification}

As we outlined earlier, there is a significant amount of intertemporal price fluctuation present in the data: in addition to frequent changes in weekly fares, there are also cross-market, departuredate and booking-week variations. The identification of the fraction of strategic consumers $\theta$ is based on the variation of price trends. As we explain shortly, the estimation is conducted for each market separately, so the identification is based on the variation of price trajectories across booking occasions and departure dates within the same market.

The presence of strategic consumers affects observed demand only when the price falls or is expected to fall. When the price increases or is expected to increase, strategic consumers behave in 
the same way as their myopic counterparts. In this case, variations in demand are attributed only to price elasticity. However, in the case of price reductions, variations in demand can be attributed to both price elasticity and strategic consumers. If we are able to quantify the changes in demand induced by price elasticity, the extra variations in demand can be attributed to strategic consumers. The question is: how do we identify price sensitivities and the fraction of strategic consumers separately? To illustrate this more precisely, recall the model under perfect foresight (Equation 4) and consider the following cases described by waiting decisions $z_{m, t-1}$ and $z_{m t}$, equivalent to price trends under perfect foresight:

$$
\begin{aligned}
& \text { Case 1: } z_{m, t-1}=0, z_{m t}=0 \Rightarrow d_{m t}=q\left(p_{m t}, X_{m}, t\right), \\
& \text { Case 2: } z_{m, t-1}=0, z_{m t}=1 \Rightarrow d_{m t}=(1-\theta) q\left(p_{m t}, X_{m}, t\right), \\
& \text { Case 3: } z_{m, t-1}=1, z_{m t}=0 \Rightarrow d_{m t}=q\left(p_{m t}, X_{m}, t\right)+\theta q\left(p_{m t}, X_{m}, t-1\right), \\
& \text { Case 4: } z_{m, t-1}=1, z_{m t}=1 \Rightarrow d_{m t}=(1-\theta) q\left(p_{m t}, X_{m}, t\right)+\theta q\left(p_{m t}, X_{m}, t-1\right) .
\end{aligned}
$$

In Case 1, the price keeps rising from time $t-1$ to $t$ and to $t+1$, so the observed sales comes down to the baseline demand $d_{m t}=q\left(p_{m t}, X_{m}, t\right)$. Thus, $q(\cdot)$ can be identified. That is, price sensitivities are identified based on occasions with increasing prices. Once the baseline demand function is identified, each of the other three cases can help identify the fraction $\theta$. Precisely, it is the variation in $z$, i.e., the price trend, that identifies the fraction of strategic consumers. Note, however, that the fraction $\theta$ is over-identified, since all three cases can help identification. This means that we can actually identify more parameters, which takes us to the identification of the time-variant fraction $\widetilde{\theta}_{t}, t=1,2, \ldots, T-1$. For example, Cases 2 and 3 can now be written as $d_{m t}=\left(1-\theta_{t}\right) q\left(p_{m t}, X_{m}, t\right)$ and $d_{m t}=q\left(p_{m t}, X_{m}, t\right)+\theta_{t-1} q\left(p_{m t}, X_{m}, t-1\right)$, respectively, which allows us to identify $\theta_{t}$ and $\theta_{t-1}$.

To see if price sensitivities are still identified when we allow for different sensitivities between strategic and non-strategic consumers, we again look at different cases classified by the value of $z_{m, t-1}, z_{m t}$,

$$
\begin{aligned}
& \text { Case 1: } z_{m, t-1}=0, z_{m t}=0 \Rightarrow d_{m t}=-\left((1-\theta) \beta_{n}+\theta \beta_{s}\right) p_{m t}+X_{m t} \gamma, \\
& \text { Case 2: } z_{m, t-1}=0, z_{m t}=1 \Rightarrow d_{m t}=-(1-\theta) \beta_{n} p_{m t}+(1-\theta) X_{m t} \gamma .
\end{aligned}
$$

From Case 2, we can identify $(1-\theta) \beta_{n}$, and $(1-\theta) \gamma$, but not $\theta, \beta_{n}, \gamma$ separately. From Case 1 , we are able to identify $\gamma$ from the variation of $X_{m t}{ }^{2}$. Together with $(1-\theta) \gamma$ identified in Case 2, we are able to identify $\theta$. Since Case 1 also identifies $\left((1-\theta) \beta_{n}+\theta \beta_{s}\right)$, together with $(1-\theta) \beta_{n}$ and $\theta$, we are able to identify $\beta_{s}$ and $\beta_{n}$. Similarly, $\theta$ is again over-identified, since there are other cases

${ }^{2}$ For simplicity, we include all variables other than price into $X_{m t}$, i.e., the constant, polynomials of $t$ and marketdeparture-date characteristics $X_{m}$. 
based on $z_{m, t-1}, z_{m t}$ which help us identify $\theta$ as well. These over-identification conditions can again be utilized to identify the vector $\widetilde{\theta}_{t}, t=1,2, \ldots, T-1$.

So far we have discussed the identification for models under perfect foresight. In fact, the same logic also carries over to models under rational expectations since the only difference is that $z_{m t}$ becomes a probability rather than a $\{0,1\}$ variable. The variation in $z$ (now $P r$ ) still serves as the source of identification for $\theta$. More precisely, under rational expectations, we first fit a model to predict strategic consumers' probability of waiting, and then use the variation in this probability to identify the fraction of strategic consumers. In summary, we obtain the identification because strategic consumers behave differently under different expectations of future prices.

\subsection{Estimation}

Note that our demand model is nonlinear in its parameters $(\theta, \beta, \gamma, \rho)$. The moment condition used in estimation has the mean independence property ${ }^{3}, E\left[\nu_{m t} \mid X_{m}, p_{m t}\right]=0$, which guarantees unbiased estimators (see Wooldridge 2010). The key challenges in estimation are 1) finding the global optimal solution to a minimization problem where the first order conditions are not linear in parameters, and 2) accounting for fixed effects and serial correlations in error terms in the nonlinear minimization problem. We design an algorithm and describe it in the appendix. Briefly, the key idea is to first transform the nonlinear problem into a linear problem to address the error structure given a partial set of parameters, and then minimize over this parameter set.

We use bootstrapping to obtain the standard errors and confidence intervals. To guarantee that all booking periods for a particular departure date in a market are selected or not selected as a whole, we use clustered bootstrapping. That is, the resampling is done at the level of market-departuredate rather than booking period. Although adjacent departure dates in the same markets might not be completely independent, the correlation is of less concern compared to the correlation of booking periods for the same departure date. In our data, 250 rounds of bootstraps are sufficient to obtain convergence in standard error estimations. However, it takes substantially more rounds $(1,000)$ to obtain an accurate estimate of the confidence interval. Since the estimates of the fraction of strategic consumers are bounded within $[0,1]$ and the bootstrapping distributions of these fractions are largely asymmetric, it is important to bootstrap the percentile confidence intervals rather than to compute the confidence intervals from standard errors.

We perform estimation market by market since each market demonstrates significantly different patterns of time trends, seasonality, day-of-week effects and price sensitivities. Pooling all markets

\footnotetext{
${ }^{3}$ After controlling for fixed effects and serial correlation, it is relatively reasonable to assume that price is uncorrelated with the remaining part of the error term. We do not find evidence of correlation between the residuals $\left(\hat{\nu}_{m t}\right)$ and prices (with a correlation less than 0.01). We also considered using previous cumulative demand and previous demand as instruments. However, they sometime show stronger correlation with the error terms than prices.
} 
together without accounting for these differences would result in misspecification of the baseline demand model, which would further bias the estimation of the fraction of strategic consumers. To mitigate this effect we would need hundreds of market-specific coefficients. Instead, the estimation is more accurate and efficient when it is performed for each market separately. On average, it took one to five hours to run 1,000 bootstraps for each market, depending on the model specification. This amounts to 100 to 500 hours of computation time for each model specification run over all markets. The long running time is largely due to the non-linearity of the model, randomized initialization to guarantee global optimality, and the large number of bootstraps. We code the program in MATLAB and we run it on the Wharton Grid Computing Platform (a 20-node, 80-CPU Linux grid and cluster environment).

6.2.1. Variables In this section, we discuss the variables used in the aforementioned models. We provide a list of these variables and their descriptions in Table 3.

Baseline Demand Model. The baseline demand is affected by the following factors. 1) Price. We use the lowest daily price among multiple candidates for the price measure. This is a good approximate price point since we care most about strategic consumers who are presumably in search of the lowest prices. On most booking days, there is no obvious deviation between the lowest price and, say, the average of the three lowest prices, except for a few days close to departure. In addition, lowest daily prices are also a commonly used measure in industry practices (e.g., Farecast) and related papers (e.g., Mantin and Gillen 2011). To aggregate daily price points to the weekly level, there are at least two options - the minimum and the average of the lowest daily prices within a week. Significant differences mostly appear in the final week before departure, when prices change rapidly from day to day. For this reason we use the average of the lowest daily prices as the measure of the weekly price; otherwise, the price sensitivity in the final weeks before departure is not well captured. 2) Booking time: booking week and its polynomials, and the final booking week before departure. 3) Departure-date characteristics. Due to seasonal demand patterns, some departure dates have higher demand than others. For example, during the vacation seasons leisure destinations experience many more travelers than they normally do. We control for demand seasonality by identifying the high-demand season from the data, which corresponds roughly to the spring break period. Seasonality is more obvious for leisure destinations than for business destinations. We also control for the day-of-week effect of the departure date using dummies. Departures tend to cluster around weekdays in business markets, and around weekends in leisure markets.

Weak-Form Rational Expectations. In this case the predictors of future prices include historical prices and other information available to the decision makers. 1) Relative fares. The current fare relative to the fare of the last period, to the initial fare, and to the average market fare obtained 
from the DB1B dataset. 2) Price volatility. The coefficient of variation of daily fares within a week ${ }^{4}$. 3) The initial price. Initial prices are highly correlated with demands across departure dates, which reflects the fact that fare managers have some knowledge of demand when making the initial pricing decision. 4) Booking time and departure date characteristics.

The Supply Model, Strong-Form Rational Expectations. The variables include last period price, cumulative demand, the initial price, booking time and departure date characteristics.

\section{Results}

Our estimations provide consistent findings of strategic consumers across markets under various model specifications. We first illustrate these findings using different model specifications applied to two representative markets, and then we summarize them across all markets. The representative markets include one leisure market, labeled as L, with Orlando, Florida as the destination and one business market, labeled as B, with Atlanta, Georgia as the destination. The origins of both markets are disguised for confidentiality reasons.

\subsection{Results under Different Baseline Demand Models}

In Table 5 we compare three different baseline demand models under perfect consumer foresight: 1) the linear model, 2) the linear model with correction of price endogeneity, and 3) the nonlinear exponential model ${ }^{5}$. As we show in the table, all models lead to similar estimates of the fraction of strategic consumers, about $3 \%$ to $5 \%$ for this particular market under perfect foresight. $(3.6 \%$ under the linear model, $5.2 \%$ under the linear model with endogeneity corrections, and $2.5 \%$ under the nonlinear model.) We select the linear model with endogeneity correction as the basis for subsequent analysis since it addresses the potential biases associated with the basic linear model and is computationally more efficient than the nonlinear model. It turns out that the linear model with endogeneity correction has the best model fit as well in terms of R-square, explaining $39 \%$ of the variation on average, and in some markets as high as $60 \%$ to $70 \%$. Comparing the results of the two linear models, we find that, as expected, price sensitivity is underestimated when the endogeneity issues are not addressed: without correction for endogeneity the price sensitivity is -0.174 , while controlling for endogeneity it is -0.224 . In this particular market, this further leads to an underestimation of the fraction of strategic consumers, i.e., 0.036 as compared to 0.052 . In other markets, we observe overestimation of the fraction.

The signs of other coefficients are in line with our expectations. We use booking week $t, t^{2}, t^{3}$ as controls for the time trend because the incremental explanatory power is minimal when adding

\footnotetext{
${ }^{4}$ Using standard deviation and coefficient of variation with or without first-differencing yield similar results.

${ }^{5}$ We also estimate a nonlinear model with correction for price endogeneity. The performance of this model turns out to be almost the same as for the basic nonlinear model, but it takes four to five times longer to estimate due to the high level of non-linearity.
} 
higher polynomial terms. We see that the final week before departure has a strong positive effect on demand, especially in business markets. Departure date characteristics (seasonality and dayof-week effects) also have significant effects on total demand. In many markets, the estimated serial correlation between adjacent demand shocks is large and significant (mildly significant in this market though), highlighting the importance of controlling for the serial correlation.

\subsection{Results under Different Consumer Expectation Assumptions}

Now we move on to compare the estimated fractions of strategic consumers under different assumptions about consumer expectation; we present the results in Table 6 . In this market we find persistent evidence of strategic consumers regardless of the assumptions about consumer expectation of future prices. Under the benchmark model, i.e., perfect foresight, the fraction of strategic consumers is significant at $5.2 \%$. Under the rational expectations assumption, the estimates are higher, as we expected: $29.2 \%$ and $38.5 \%$ under strong-form and weak-form rational expectation, respectively. All estimates are statistically significant. Naturally, the results from the rational expectations model are likely to be closer to the truth since in reality it is not possible to predict future prices perfectly. One also needs to be cautious when comparing these fractions: although the estimate under rational expectations can be significantly higher than that under perfect foresight, it does not necessarily mean more strategic waiting. Ultimately, the demand shift observed due to strategic consumers is also dependent on consumers' ability to make predictions of future prices. Since some consumers are not able to correctly anticipate future prices, they would not behave "strategically" when they should. However, there is a possibility that with the proliferation of web tools such as fare charts and fare alerts, consumers are becoming better at making price predictions. The demand shifting effect will become more prominent in this case. Estimates of other control variables are consistent across three models and are of expected signs. The results of the prediction models used in the weak-form and the strong-form rational expectations are shown in Appendix Table 12.

\subsection{Heterogeneity in Price Sensitivities}

Strategic consumers may have different price sensitivity from myopic consumers. As we see in the identification section, estimations of price sensitivity and of the fraction of strategic consumers are closely related to each other. Therefore, there may be a concern that the fraction of strategic consumers we identify could be partially driven by the different price sensitivities of these two consumer groups. To investigate this possibility, we estimate different price sensitivities for strategic and myopic consumers. The results are shown in Table 7. For the leisure Market L, we do not observe significant differences in the price sensitivities among these two groups, and hence the estimates of strategic fractions do not change much. However, for the business Market B, we do observe a significant difference in price sensitivities among these two groups. As we discussed 
earlier, the observed fraction $\theta_{\text {obs }}$ of strategic consumers at a particular price point is not the same as the parameter $\theta$. In Market $\mathrm{L}$, the two estimates are similar since the difference between the two price sensitivities is small. In Market $\mathrm{B}$, however, $\theta_{\text {obs }}$ is much less than $\theta$.

Finally, we summarize the estimation results over all markets in Table 8 using histograms. For each market in our data, we estimate the strong-form rational expectation model under the same price sensitivity and different price sensitivities. We obtain on average $24 \%$ strategic consumers under the former and $17 \%$ under the latter. We also find a sizable heterogeneity across markets, with standard deviations of $12 \%$ and $11 \%$, respectively. To investigate how strategic behavior is affected by the market characteristics, we regressed the fraction (the logistic transformation of the fraction) on market characteristics such as level of competition, presence of low-cost carriers, distance and origin demographics, destination types (business vs. leisure), distribution channel (online vs. offline), and market size. The results are displayed in Table 9. We find that markets with shorter distance, higher income at the origin city, and smaller market size tend to have more strategic consumers. Given the number of markets we have, our ability to expand this analysis is limited.

\subsection{Time-Variant Fraction of Strategic Consumers}

To investigate the arrival pattern of strategic consumers over booking time, we estimate nonparametrically a time-variant vector of the fractions of strategic consumers. To show the general pattern, we group the results by destination, since the trend of the fraction over time for routes with the same destination are similar. Figure 1 shows the fraction of strategic consumers over twelve booking periods before the final booking period, estimated under strong-form rational expectation and with heterogeneity in price sensitivities. As we see in the figure, the fraction of strategic consumers is higher at the beginning of the booking horizon, that is, when risk and waiting costs are lower, or close to departure, likely in search of last-minute deals. This pattern is less prominent in popular markets such as Las Vegas (LAS) and Orlando (MCO), which is in line with the observation that last-minute deals are often offered in less-popular markets where there is distressed inventory. Those consumers who arrive for the last-minute deals are also flexible in their travel schedules, so they can decide to travel without much advance planning if the price is low, or decide not to travel if the price is high.

\section{Counterfactual Analysis}

Now that we have robust evidence of strategic consumers, what are the revenue implications? What strategies should airlines take in response? We answer these questions using counterfactual analysis. We focus on 1) the revenue impact of the presence of strategic consumers, and 2) alternative pricing schemes to eliminate strategic waiting. 


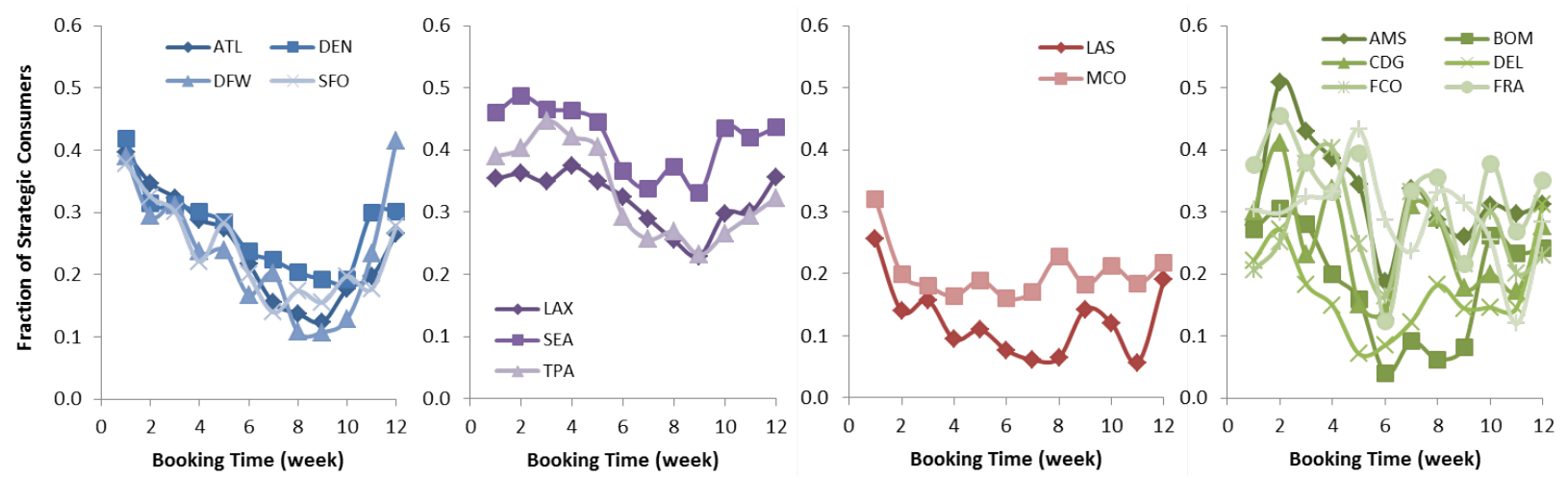

Figure 1 Fraction of Strategic Consumers Varying with Booking Time (grouped by destination)

\subsection{Revenue Impact of Strategic Consumers}

The commonly held belief regarding strategic consumers is that they pose a threat to the revenues of the firms (see Anderson and Wilson 2003, Aviv and Pazgal 2008, Levin et al. 2009). Surprisingly, we find from our counterfactual analysis that this is not always true. As a matter of fact, strategic waiting may sometimes benefit the seller, an effect that is in line with the predictions by $\mathrm{Su}(2007)$ and Cho et al. (2008). Table 10 illustrates this through two examples, based on 100 simulations using the most complex model specification with heterogeneity in price sensitivity and time-variant fraction of strategic consumers. The results hold across other model specifications as well. Under rational expectations, each simulation involves computing a new equilibrium of consumer beliefs and actual future prices. We ask the following question: how much will revenues change if all consumers turn from myopic to strategic? To isolate the effect of price sensitivities and the effect of being strategic, we let myopic consumers become strategic without changing their original price sensitivities. As shown in Column 5, for business markets such as Market B, revenue decreases by $0.40 \%$ to $1.01 \%$, while in leisure markets such as Market L, revenue increases by $0.22 \%$ to $1.39 \%$ (with small standard deviations in both markets). This pattern is not specific to these two example markets but holds in general, as we demonstrate shortly.

To explain the phenomenon, consider the two effects of strategic consumers: the price-reduction effect and the demand-increasing effect. Strategic consumers drive down prices, and as a result firms cannot charge high prices even to high-value customers. Yet strategic consumers drive up demand in two ways. While the first is obvious - demand is higher since prices are lowerthe second is more subtle. Some low-value customers will not buy at the price when they first arrive. The flexibility of being able to come back in later periods offers them more purchasing chances, and they may end up buying. Which effect dominates depends on the heterogeneity in the composition of high-value and low-value customers in the market. In business markets with proportionally more high-value customers, the price-reduction effect dominates, whereas in leisure 
markets with proportionally more low-value customers, the demand-increasing effect dominates. Table 10 illustrates the dominant effect for each market. The average price decreases by $2.55 \%$ in business market B, similar to that $(2.85 \%$ ) in leisure market L assuming perfect foresight (or $0.71 \%$ compared to $0.65 \%$ assuming rational expectation); however, demand increases by only $1.59 \%$ in business market B, much smaller than the $4.36 \%$ increase in leisure market L (or $0.31 \%$ compared to $0.88 \%$ assuming rational expectation).

We present summaries and histograms of the impacts of strategic consumers on revenues across all markets in the left panel of Table 11. The ranges of revenue impacts are $[-2.7 \%, 1.0 \%]$ under perfect foresight and $[-1.0 \%, 0.8 \%]$ under rational expectations, as measured by the 5th and 95th percentiles. Since our data includes inventory classes, we are able to compute the percentage of consumers who purchased full fares (inventory class $\mathrm{Y}$ and B) as a measure of the extent to which the route is a business route. This measure is negatively correlated with the revenue impact. The coefficient of correlation is -0.366 and -0.216 under perfect foresight and rational expectations, respectively, suggesting that the more "business" the route is, the more likely it is that the presence of strategic consumers will have a negative effect on the revenues. Plus, we find no significant effect of competition when regressing the revenue changes on various market characteristics. Table 10 also shows that the effects of strategic consumers tend to be more negative when they are more sophisticated in their prediction of future prices.

\subsection{Non-Decreasing Price Commitment}

One common approach to eliminate strategic waiting is to commit to fixed or non-decreasing price paths, which is the practice often used by low-cost carriers. For example, Southwest has much more transparent and simpler fare structures than the legacy airlines, and their prices only go up as the departure date approaches, except for some occasional temporary sales. The question is: would it be better for airlines to commit to non-decreasing prices? Computing the optimal non-decreasing price path is itself a question requiring separate analytical efforts beyond the scope of this paper. Instead, we examine the impact of a heuristic non-decreasing price scheme which adds a small twist to the current pricing strategy. We take the current pricing strategy and use it to predict a candidate price point for the next period. We set the future price as the maximum of this candidate price and the current price to guarantee that it is non-decreasing.

Column 6 in Table 10 shows that for business markets where strategic consumers are undesirable, commitment to non-decreasing price ensures higher revenues $-2.9 \%$ to $3.6 \%$ higher in this example. However, on the leisure markets, such commitment would not be beneficial to the firms: revenues decrease by $2.4 \%$ to $3.7 \%$ in the example. The impacts of committing to non-decreasing price schemes across different markets are presented in the right panel of Table 11. The ranges 
of the revenue gains are $[-1.4 \%, 9.2 \%]$ under perfect foresight and $[-1.1 \%, 10.6 \%]$ under rational expectations, as measured by the 5th and 95th percentiles. The coefficient of correlation between the measure of how business-like the market is and the revenue gains is positive, i.e., 0.249 and 0.220 under perfect foresight and rational expectations, respectively. This suggests that the more business-like the route is, the more likely airlines to benefit from non-decreasing price commitment.

\section{Conclusions and Discussions}

We provide evidence of strategic consumers in the air-travel industry, and this evidence is robust to various modeling assumptions. We obtain an estimate of $4.9 \%$ to $44.9 \%$ proportion of strategic consumers on average across markets under rational expectation assumption. We find that the fraction of strategic consumers varies significantly across markets, and that strategic consumers tend to arrive either at the beginning of the booking horizon or close to departure.

Contrary to the predominant belief, our counterfactual analysis shows that strategic consumers do not always hurt revenues; the effect differs by market type. In business markets, where a large proportion of consumers are relatively price-inelastic, high value consumers, the presence of strategic consumers tends to drive down the total revenue through lower prices. However, in leisure markets, the presence of strategic consumers may boost market revenue by inducing higher demand. Therefore, commitment to non-decreasing prices is more likely to be beneficial in business markets than in leisure markets. The median revenue improvements on those markets that benefit from this pricing strategy is $3.5 \%$, with quantiles $1.8 \%$ and $5.6 \%$.

Our results have important implications for both theory and practice. In many industries with significant price fluctuations over time it is crucial to model consumers' inter-temporal choices, and we propose a structural model for this purpose. Failing to do so will result in suboptimal pricing or inventory decisions. Practically, our counterfactual analysis provides important guidance to airline managers: improve demand forecasts accounting for inter-temporal demand substitution, assess the impact of strategic consumers, and decide in what circumstances it would be desirable to eliminate strategic waiting and what is the potential benefit. Our approach can also be applied to many other industries to help firms figure out whether their business is subject to the presence of strategic consumers, and what action they should take in response.

Naturally, our study is not free of limitations, which offer many avenues for future research. As we discussed earlier, we do not model details of inter-firm competition, which merits a separate paper. Other most obvious restrictions and assumptions are a single waiting time period (rather than multiple); a discrete, two-point distribution of strategic consumer behavior (rather than a continuous distribution); and weekly aggregation of the data. We also conduct only limited counterfactual analysis: a separate study might attempt to devise an entirely new optimization 
algorithm to maximize revenues. These and other extensions will inevitably run into computational difficulties, and resolving them will be part of the challenge.

\section{References}

Anderson, C.K., J.G. Wilson. 2003. Wait or buy? The strategic consumer: pricing and profit implications. Journal of the Operational Research Society 54(3) 299-306.

Aviv, Y., A. Pazgal. 2008. Optimal pricing of seasonal products in the presence of forward-looking consumers. Manufacturing \& Service Operations Management 10(3) 339-359.

Belobaba, P.P. 1989. Application of a probabilitics decision model to airline seat inventory control. Operations Research 37(2) 183-197.

Borenstein, S., N.L. Rose. 1994. Competition and Price Dispersion in the U.S. Airline Industry. The Journal of Political Economy 102(4) 653-683.

Boyd, E.A. 2007. The Future of Pricing: How Airline Ticket Pricing Has Inspired a Revolution. PalgraveMacMillan, New York.

Cachon, G.P., R. Swinney. 2009. Purchasing, pricing, and quick response in the presence of strategic consumers. Management Science 55(3) 497-511.

Chellapp, R.K., R.G. Sin, S. Siddarth. 2011. Price Formats as a Source of Price Dispersion: A Study of Online and Offine Prices in the Domestic U.S. Airline Markets. Information Systems Research 22(1) 83-98.

Chevalier, J., A. Goolsbee. 2009. Are durable goods consumers forward-looking? Evidence from the college textbooks. The Quarterly Journal of Economics 124(4) 1853-1884.

Cho, M., M. Fan, Y.P. Zhou. 2008. Strategic consumer response to dynamic pricing of perishable products. Working paper, University of Washington, Seattle, WA.

Clemons, E.K., L. Hitt, I.H. Hann. 2002. Price dispersion and differentiation in online travel: An empirical investigation. Management Science 48(4) 534-550.

Dillon, W.R., A. Kumar. 1994. Latent structure and other mixture models in marketing: An integrative survey and overview. R.P. Bagozz, ed., Advanced ethods of Marketing Research. Blackwell Publisher, Cambridge, $352-388$.

Erdem, T., M.P. Keane. 1996. Decision-making under uncertainty: Capturing dynamic choice processes in turbulent consumer goods markets. Marketing Science 15(1) 1-20.

Etzioni, O., R. Tuchinda, C.A. Knoblock, A. Yates. 2003. To buy or not to buy: Mining airfare data to minimize ticket purchase price. In Proceedings of KDD03. ACM Press, 119-128.

Gallego, G.R., G. van Ryzin. 1994. Optimal dynamic pricing of inventories with stochastic demand over finite horizons. Marketing Science 40(8) 999-1020. 
Granados, N.F., A. Gupta, R.J. Kauffman. 2011. Online and offline demand and price elasticities: Evidence from the air travel industry. Information Systems Research Forthcoming.

Hendel, I., A. Nevo. 2006. Measuring the implications of sales and consumer inventory behavior. Econometrica $\mathbf{7 4}(6)$ 1637-1673.

Hendel, I., A. Nevo. 2011. Intertemporal price discrimination in storable good markets. Working paper, Northwestern University, Evanston, IL.

Jerath, K., S. Netessine, S.K. Veeraraghavan. 2010. Revenue management with strategic customers: Lastminute selling and opaque selling. Management Science 56(3) 430-448.

Levin, Y., J. McGill, M. Nediak. 2009. Dynamic pricing in the presence of strategic consumers and oligopolistic competition. Management Science 55(1) 32-46.

Liu, Q., G.J. van Ryzin. 2008. Strategic capacity rationing to induce early purchases. Management Science 54(6) 1115-1131.

Magnac, T., D. Thesmar. 2002. Identifying dynamic discrete decision processes. Econometrica 70(2) 801-816.

Mantin, B., D. Gillen. 2011. The hidden information content of price movements. European Journal of Operational Research Forthcoming.

Nair, H. 2007. Intertemporal price discrimination with forward-looking consumers: Application to the us market for console video-games. Quantitative Marketing and Economics 5(3) 239-292.

Netessine, S., C. Tang, eds. 2009. Consumer-driven demand and operations management models. Springer Publisher, New York, NY.

Newman, J.P., M.E. Ferguson, L.A. Garrow. 2010. Estimation of choice-based models using sales data from a single firm. Working paper, Georgia Institute of Technology, Atlanta, GA.

Osadchiy, N., E. Bendoly. 2010. Are consumers really strategic? Implications from an experimental study. Working paper, Emory University, Atlanta, GA.

Rust, J. 1994. Structural estimation of markov decision processes. R. Engle, D. McFadden, eds., Handbook of Econometrics, vol. 4. Elsevier, Amsterdam: North Holland, 3081-3143.

Shen, Z.M., X. Su. 2007. Customer behavior modeling in revenue management and auctions: A review and new research opportunities. Production and Operations Management 16(6) 713-728.

$\mathrm{Su}$, X. 2007. Inter-temporal pricing with strategic consumer behavior. Management Science 53(5) 726-741.

Talluri, K.T., G.J. van Ryzin. 2005. The Theory and Practice of Revenue Management. Springer, New York.

Vulcano, G., G. van Ryzin, W. Chaar. 2010. Choice-based revenue management: An empirical study of estimation and optimization. Manufacturing and Service Operations Management 12(3) 371-392.

Wooldridge, J.M. 2010. Econometric analysis of cross section and panel data, chap. 12. MIT Press, Cambridge, MA. 
Table 1 Summary Statistics of Demand and Price

\begin{tabular}{rcccc}
\hline & mean & std & min & $\max$ \\
\hline total passengers by market departure date & 90.1 & 110.0 & 0 & 1436 \\
weekly passengers & 6.4 & 13.3 & 0 & 309 \\
weekly average fare (weighted) $(\$)$ & 370.35 & 288.58 & 110.33 & 4284.33 \\
\hline
\end{tabular}

Table 2 Fare Fluctuations over Markets/Departure Dates/Booking Time

\begin{tabular}{|c|c|c|c|}
\hline & decrease(fraction) & no change(fraction) & increase(fraction) \\
\hline \multicolumn{4}{|c|}{ daily lowest fare } \\
\hline mean & 0.279 & 0.472 & 0.249 \\
\hline \multicolumn{4}{|c|}{ weekly fare (average of daily lowest fare) } \\
\hline mean & 0.395 & 0.093 & 0.512 \\
\hline range by market & {$[0.170,0.561]$} & {$[0.004,0.363]$} & {$[0.322,0.630]$} \\
\hline range by departure date & {$[0.300,0.477]$} & {$[0.042,0.153]$} & {$[0.408,0.644]$} \\
\hline by booking week 1 & $0.450^{\dagger}$ & 0.175 & 0.375 \\
\hline 2 & 0.499 & 0.135 & 0.367 \\
\hline 3 & 0.474 & 0.138 & 0.388 \\
\hline 4 & 0.413 & 0.133 & 0.454 \\
\hline 5 & 0.449 & 0.106 & 0.445 \\
\hline 6 & 0.435 & 0.084 & 0.481 \\
\hline 7 & 0.446 & 0.071 & 0.483 \\
\hline 8 & 0.425 & 0.076 & 0.499 \\
\hline 9 & 0.460 & 0.080 & 0.460 \\
\hline 10 & 0.456 & 0.073 & 0.471 \\
\hline 11 & 0.198 & 0.035 & 0.767 \\
\hline 12 & 0.035 & 0.006 & 0.959 \\
\hline
\end{tabular}

Table 3 Variable Descriptions

\begin{tabular}{|c|c|}
\hline Category & Variable \\
\hline \multicolumn{2}{|c|}{ (1) Reduced-Form Regressions and Baseline Demand Model } \\
\hline $\begin{array}{l}\text { price } \\
\text { booking time } \\
\text { departure date characteristics }\end{array}$ & $\begin{array}{l}\text { weekly price: average of daily lowest prices within a week } \\
\text { polynomials of booking week; final booking week dummy before departure } \\
\text { high-demand season; day-of-week dummies }\end{array}$ \\
\hline \multicolumn{2}{|c|}{ (2) Predicting the Probability of Prices Falling for Weak-Form Rational Expectation } \\
\hline $\begin{array}{l}\text { price volatility } \\
\text { initial price } \\
\text { other measures }\end{array}$ & $\begin{array}{l}\text { current_to_last: current week price divided by final week price } \\
\text { current_to_initial: current week price divided by the first week price } \\
\text { current_to_mktavg: current week price divided by the average market price } \\
\text { the coefficient of variance of the daily prices in the current week } \\
\text { initial price } \\
\text { booking time and departure day characteristics }\end{array}$ \\
\hline \multicolumn{2}{|c|}{ (3) Supply Model, Strong-Form Rational Expectation } \\
\hline $\begin{array}{l}\text { price history } \\
\text { demand history } \\
\text { initial price } \\
\text { other measures }\end{array}$ & $\begin{array}{l}\text { price lagged by one period } \\
\text { cumulative demand } \\
\text { initial price } \\
\text { booking time and departure day characteristics }\end{array}$ \\
\hline
\end{tabular}


Table 4 Reduced-Form Regressions of Demand on (Expected) Future and Past Prices

\begin{tabular}{|c|c|c|c|}
\hline & $\begin{array}{l}\text { (1) } \\
\text { current price }\end{array}$ & $\begin{array}{l}(2) \\
\text { realized future } \\
\text { and past prices }\end{array}$ & $\begin{array}{c}\text { (3) } \\
\text { expected prices }\end{array}$ \\
\hline price $\left(p_{t}\right)$ & $\begin{array}{r}-0.044 \\
(0.021)\end{array}$ & $\begin{array}{r}-0.081 \\
(0.041)\end{array}$ & $\begin{array}{r}-0.177 \\
(0.046)\end{array}$ \\
\hline$p_{t+1}$ & & $\begin{array}{r}0.150 \\
(0.026)\end{array}$ & \\
\hline$p_{t-1}$ & & $\begin{array}{r}-0.087 \\
(0.041)\end{array}$ & $\begin{array}{r}0.362 \\
(0.165)\end{array}$ \\
\hline expected price $\hat{p}_{t+1}$ & & & $\begin{array}{r}0.300 \\
(0.040)\end{array}$ \\
\hline$\hat{p}_{t}$ & & & $\begin{array}{r}-0.463 \\
(0.171)\end{array}$ \\
\hline booking time $t$ & $\begin{array}{r}4.224 \\
(2.695)\end{array}$ & $\begin{array}{r}-1.187 \\
(2.748)\end{array}$ & $\begin{array}{r}9.783 \\
(4.762)\end{array}$ \\
\hline$t^{2}$ & $\begin{array}{r}-0.985 \\
(0.472)\end{array}$ & $\begin{array}{r}0.147 \\
(0.491)\end{array}$ & $\begin{array}{l}-1.834 \\
(0.921)\end{array}$ \\
\hline$t^{3}$ & $\begin{array}{r}0.088 \\
(0.024)\end{array}$ & $\begin{array}{r}0.022 \\
(0.026)\end{array}$ & $\begin{array}{r}0.122 \\
(0.050)\end{array}$ \\
\hline final week & $\begin{array}{r}25.113 \\
(5.222)\end{array}$ & $\begin{array}{r}84.738 \\
(12.166)\end{array}$ & $\begin{array}{r}145.341 \\
(17.367)\end{array}$ \\
\hline high season & $\begin{array}{r}4.450 \\
(2.102)\end{array}$ & $\begin{array}{r}3.419 \\
(2.050)\end{array}$ & $\begin{array}{r}5.875 \\
(2.358)\end{array}$ \\
\hline day-of-week dummies & yes & yes & yes \\
\hline const & $\begin{array}{r}8.740 \\
(6.681)\end{array}$ & $\begin{array}{r}8.893 \\
(7.287)\end{array}$ & $\begin{array}{r}-16.116 \\
(8.989)\end{array}$ \\
\hline R-square & 0.7300 & 0.7466 & 0.7554 \\
\hline
\end{tabular}

Note: Standard errors are shown in parentheses.

Table 5 Compare Different Baseline Demand Models (perfect foresight): Market $\mathbf{L}$

\begin{tabular}{|c|c|c|c|}
\hline & $\begin{array}{l}(1) \\
\text { linear }\end{array}$ & $\begin{array}{c}(2) \\
\text { linear }+ \text { fixed } \\
\text { effect }+ \text { AR1 }\end{array}$ & $\begin{array}{c}(3) \\
\text { nonlinear }\end{array}$ \\
\hline $\begin{array}{r}\text { fraction } \\
95 \% \text { confidence interval }\end{array}$ & $\begin{array}{r}0.036 \\
{[0.000,0.114]}\end{array}$ & $\begin{array}{r}0.052 \\
{[0.001,0.122]}\end{array}$ & $\begin{array}{r}0.025 \\
{[0.000,0.112]}\end{array}$ \\
\hline price & $\begin{array}{c}-0.174 \\
(0.038)\end{array}$ & $\begin{array}{l}-0.224 \\
(0.031)\end{array}$ & $\begin{array}{r}-0.005 \\
(0.001)\end{array}$ \\
\hline booking time $t$ & $\begin{array}{r}-0.107 \\
(3.300)\end{array}$ & $\begin{array}{r}-10.293 \\
(3.611)\end{array}$ & $\begin{array}{r}0.196 \\
(0.136)\end{array}$ \\
\hline$t^{2}$ & $\begin{array}{r}0.811 \\
(0.572)\end{array}$ & $\begin{array}{r}2.252 \\
(0.618)\end{array}$ & $\begin{array}{r}-0.003 \\
(0.025)\end{array}$ \\
\hline$t^{3}$ & $\begin{array}{l}-0.047 \\
(0.028)\end{array}$ & $\begin{array}{l}-0.109 \\
(0.030)\end{array}$ & $\begin{array}{r}0.000 \\
(0.001)\end{array}$ \\
\hline final week & $\begin{array}{r}8.695 \\
(4.063)\end{array}$ & $\begin{array}{r}16.266 \\
(4.201)\end{array}$ & $\begin{array}{r}0.234 \\
(0.106)\end{array}$ \\
\hline high season & $\begin{array}{r}46.345 \\
(11.125)\end{array}$ & & $\begin{array}{r}1.159 \\
(0.324)\end{array}$ \\
\hline day-of-week dummies & yes & & yes \\
\hline const & $\begin{array}{r}49.520 \\
(9.937)\end{array}$ & & $\begin{array}{r}3.323 \\
(0.536)\end{array}$ \\
\hline $\operatorname{AR} 1(\rho)$ & & $\begin{array}{r}0.117 \\
(0.064)\end{array}$ & \\
\hline R-square & 0.2470 & 0.3937 & 0.2478 \\
\hline
\end{tabular}


Table 6 Results under Different Consumer Expectation Assumptions: Market L

\begin{tabular}{|c|c|c|c|}
\hline & $\begin{array}{c}\text { (1) } \\
\text { perfect } \\
\text { foresight }\end{array}$ & $\begin{array}{c}(2) \\
\text { strong-form } \\
\text { rational expectation }\end{array}$ & $\begin{array}{c}(3) \\
\text { weak-form } \\
\text { rational expectation }\end{array}$ \\
\hline fraction of strategic consumers & 0.052 & 0.292 & 0.385 \\
\hline $95 \%$ confidence interval & {$[0.001,0.122]$} & {$[0.151,0.541]$} & {$[0.198,0.394]$} \\
\hline price & $\begin{array}{c}-0.224 \\
(0.031)\end{array}$ & $\begin{array}{r}-0.224 \\
(0.032)\end{array}$ & $\begin{array}{r}-0.214 \\
(0.031)\end{array}$ \\
\hline \multirow{2}{*}{ booking time $t$} & -10.293 & -10.160 & -6.814 \\
\hline & $(3.611)$ & $(3.612)$ & $(3.542)$ \\
\hline \multirow[t]{2}{*}{$t^{2}$} & 2.252 & 2.328 & 1.781 \\
\hline & $(0.618)$ & $(0.619)$ & $(0.598)$ \\
\hline \multirow[t]{2}{*}{$t^{3}$} & -0.109 & -0.117 & -0.091 \\
\hline & $(0.030)$ & $(0.030)$ & $(0.029)$ \\
\hline \multirow[t]{2}{*}{ final week } & 16.266 & 20.340 & 17.263 \\
\hline & $(4.201)$ & $(4.856)$ & $(4.416)$ \\
\hline \multirow[t]{2}{*}{$\operatorname{AR1}(\rho)$} & 0.117 & 0.033 & 0.045 \\
\hline & $(0.064)$ & $(0.073)$ & $(0.080)$ \\
\hline R-square & 0.3937 & 0.4073 & 0.4215 \\
\hline
\end{tabular}

Table 7 Allowing for Different Price Sensitivities between Myopic and Strategic Consumers

\begin{tabular}{|c|c|c|c|c|c|c|}
\hline & $\begin{array}{r}\text { perfect } \\
\text { foresight }\end{array}$ & $\begin{array}{c}\text { Market } L \\
\text { strong-form } \\
\text { rational }\end{array}$ & $\begin{array}{l}\text { weak-form } \\
\text { rational }\end{array}$ & $\begin{array}{r}\text { perfect } \\
\text { foresight }\end{array}$ & $\begin{array}{c}\text { Market } B \\
\text { strong-form } \\
\text { rational }\end{array}$ & $\begin{array}{l}\text { weak-form } \\
\text { rational }\end{array}$ \\
\hline fraction $(\theta)$ & 0.094 & 0.275 & 0.378 & 0.107 & 0.186 & 0.120 \\
\hline $95 \%$ confidence interval & {$[0.008,0.182]$} & {$[0.106,0.391]$} & {$[0.158,0.548]$} & {$[0.002,0.201]$} & {$[0.004,0.367]$} & {$[0.007,0.250]$} \\
\hline observed fraction $\left(\theta_{o b s}\right)$ & 0.038 & 0.286 & 0.351 & 0.036 & 0.048 & 0.026 \\
\hline $95 \%$ confidence interval & {$[0.004,0.097]$} & {$[0.127,0.435]$} & {$[0.174,0.511]$} & {$[0.000,0.093]$} & {$[0.000,0.142]$} & {$[0.000,0.105]$} \\
\hline \multicolumn{7}{|l|}{ price } \\
\hline \multirow[t]{2}{*}{ non-strategic $\left(\beta_{n}\right)$} & -0.228 & -0.229 & -0.216 & -0.013 & -0.024 & -0.026 \\
\hline & $(0.032)$ & $(0.031)$ & $(0.030)$ & $(0.032)$ & $(0.017)$ & $(0.016)$ \\
\hline \multirow[t]{2}{*}{$\operatorname{strategic}\left(\beta_{s}\right)$} & -0.311 & -0.187 & -0.206 & -0.131 & -0.201 & -0.341 \\
\hline & $(0.335)$ & $(0.125)$ & $(0.066)$ & $(0.364)$ & $(0.392)$ & $(0.510)$ \\
\hline \multirow[t]{2}{*}{ booking time $t$} & -9.773 & -10.332 & -6.805 & 6.365 & 4.474 & 4.285 \\
\hline & $(3.609)$ & $(3.745)$ & $(3.243)$ & $(2.135)$ & $(1.476)$ & (1.354) \\
\hline \multirow[t]{2}{*}{$t^{2}$} & 2.169 & 2.354 & 1.778 & -1.219 & -0.986 & -0.971 \\
\hline & $(0.622)$ & $(0.640)$ & $(0.562)$ & $(0.335)$ & $(0.254)$ & $(0.241)$ \\
\hline \multirow[t]{2}{*}{$t^{3}$} & -0.105 & -0.118 & -0.091 & 0.085 & 0.077 & 0.077 \\
\hline & $(0.031)$ & $(0.031)$ & $(0.028)$ & $(0.017)$ & $(0.013)$ & $(0.013)$ \\
\hline \multirow[t]{2}{*}{ final week } & 13.219 & 22.111 & 17.378 & 2.951 & 2.341 & 2.643 \\
\hline & $(5.077)$ & $(6.808)$ & $(6.358)$ & $(4.969)$ & $(4.745)$ & $(4.705)$ \\
\hline \multirow[t]{2}{*}{ const } & 0.094 & 0.044 & 0.050 & 0.488 & 0.572 & 0.587 \\
\hline & $(0.062)$ & $(0.063)$ & $(0.074)$ & $(0.102)$ & $(0.065)$ & $(0.059)$ \\
\hline R-square & 0.3951 & 0.4076 & 0.4216 & 0.5965 & 0.6090 & 0.6108 \\
\hline
\end{tabular}


Table 8 Fraction of Strategic Consumers over All Markets (strong-form rational expectation)

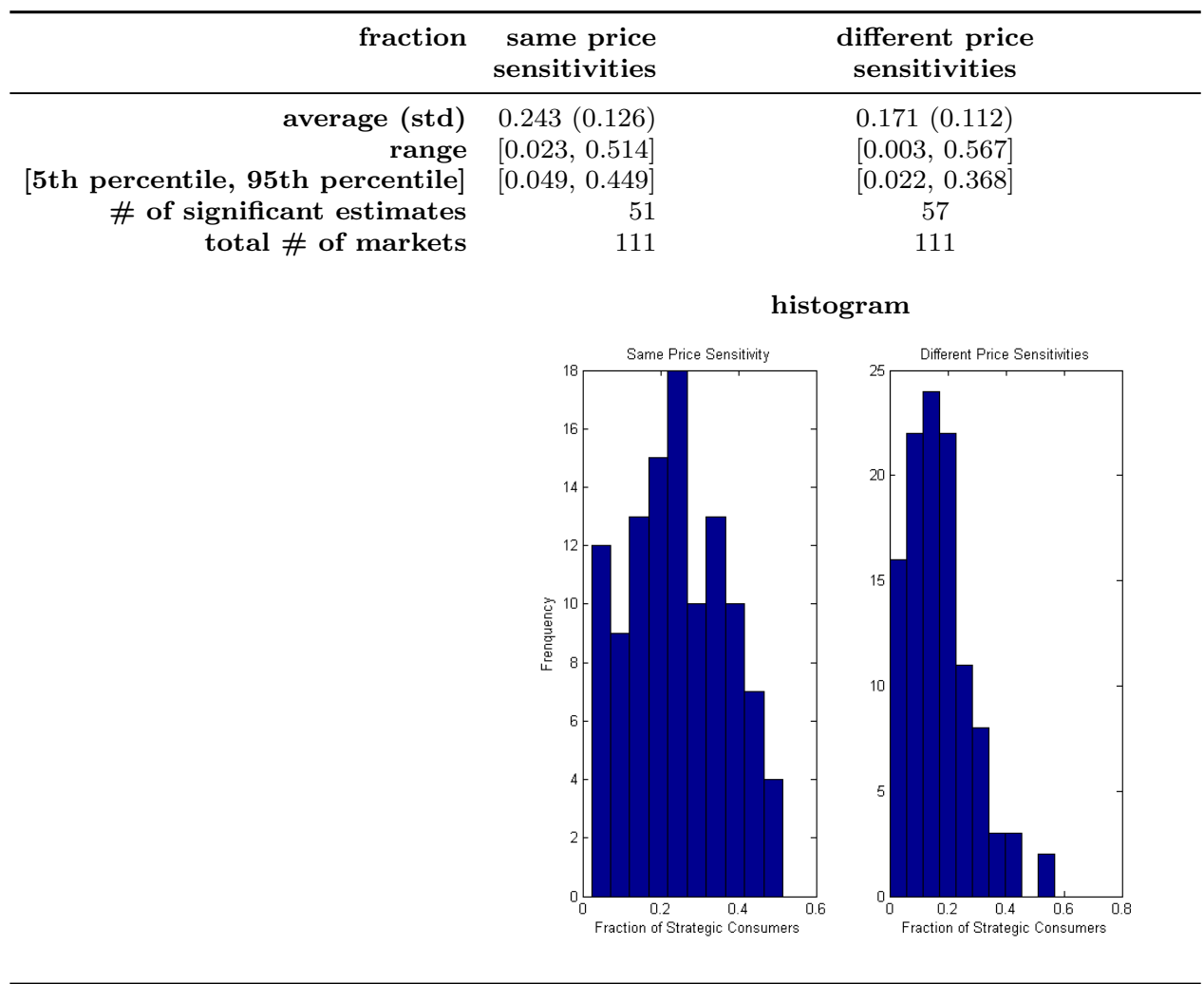

Table 9 Explaining Strategic Behavior Using Market Characteristics

\begin{tabular}{|c|c|c|}
\hline & same price elasticities & different price elasticities \\
\hline \multirow[t]{2}{*}{ business market (avg \% of full fare) } & 1.907 & 1.572 \\
\hline & $(1.358)$ & $(1.410)$ \\
\hline \multirow[t]{2}{*}{ HHI } & $1.099^{*}$ & 1.023 \\
\hline & $(0.597)$ & $(0.619)$ \\
\hline \multirow[t]{2}{*}{ low cost carrier market share } & -0.033 & -0.170 \\
\hline & $(0.792)$ & $(0.822)$ \\
\hline \multirow[t]{2}{*}{$\%$ of tickets distributed online } & $1.490^{*}$ & 1.443 \\
\hline & $(0.845)$ & $(0.877)$ \\
\hline \multirow[t]{2}{*}{ intl destination } & 0.356 & 0.500 \\
\hline & $(0.317)$ & $(0.329)$ \\
\hline \multirow[t]{2}{*}{$\ln ($ distance $)$} & $-0.407 * *$ & $-0.382^{* *}$ \\
\hline & $(0.153)$ & $(0.159)$ \\
\hline \multirow[t]{2}{*}{$\ln$ (origin population) } & 0.162 & 0.079 \\
\hline & $(0.137)$ & $(0.142)$ \\
\hline \multirow[t]{2}{*}{$\ln ($ origin per capita income) } & $1.386^{*}$ & $1.652^{* *}$ \\
\hline & $(0.724)$ & $(0.751)$ \\
\hline \multirow[t]{2}{*}{$\ln ($ market size $)$} & $-0.240^{* *}$ & $-0.227^{* *}$ \\
\hline & $(0.109)$ & $(0.113)$ \\
\hline \multirow[t]{2}{*}{ constant } & $-14.503^{* *}$ & $-16.333^{* *}$ \\
\hline & $(7.132)$ & $(7.404)$ \\
\hline \# of obs (\# of markets) & 111 & 111 \\
\hline R-square & 0.2372 & 0.2026 \\
\hline
\end{tabular}


Table 10 Counterfactual Analysis

\begin{tabular}{|c|c|c|c|c|c|c|c|}
\hline & daily & $\begin{array}{c}(1) \\
\text { all } \\
\text { myopic }\end{array}$ & $\begin{array}{c}(2) \\
\text { current }\end{array}$ & $\begin{array}{c}(3) \\
\text { all } \\
\text { strategic }\end{array}$ & $\begin{array}{c}(4) \\
\text { monotone } \\
\text { price }\end{array}$ & $\begin{array}{c}(5)=(3)-(1) \\
\text { strategic } \\
\text { - myopic }\end{array}$ & $\begin{array}{c}(6)=(4)-(2) \\
\text { gains from } \\
\text { monotone price }\end{array}$ \\
\hline & & \multicolumn{6}{|c|}{ Market L (leisure) } \\
\hline perfect & revenue $(\$ 1,000)$ & 102.2 & 102.45 & 103.62 & 98.71 & $1.39 \%(0.16 \%)$ & $-3.66 \%(0.43 \%)$ \\
\hline \multirow{3}{*}{ foresight } & demand (\# of pax) & 405.66 & 407.09 & 423.36 & 356.39 & $4.36 \%$ & $-12.45 \%$ \\
\hline & weighted price $(\$)$ & 252.02 & 251.75 & 244.84 & 277.04 & $-2.85 \%$ & $10.06 \%$ \\
\hline & price $(\$)$ & 242.97 & 243.03 & 242.19 & 261.1 & $-0.32 \%$ & $7.44 \%$ \\
\hline strong-form & revenue $(\$ 1,000)$ & 104.99 & 104.88 & 105.22 & 102.34 & $0.22 \%(0.08 \%)$ & $-2.42 \%(0.36 \%)$ \\
\hline rational & demand (\# of pax) & 414.25 & 414.11 & 417.88 & 368.61 & $0.88 \%$ & $-10.98 \%$ \\
\hline \multirow[t]{3}{*}{ expectation } & weighted price $(\$)$ & 253.51 & 253.34 & 251.87 & 277.71 & $-0.65 \%$ & $9.63 \%$ \\
\hline & price $(\$)$ & 243.79 & 243.59 & 241.77 & 261.46 & $-0.83 \%$ & $7.34 \%$ \\
\hline & & \multicolumn{6}{|c|}{ Market B (business) } \\
\hline perfect & revenue $(\$ 1,000)$ & 55.359 & 55.377 & 54.801 & 56.954 & $-1.01 \%(0.19 \%)$ & $2.85 \%(0.34 \%)$ \\
\hline \multirow[t]{3}{*}{ foresight } & demand (\# of pax) & 197.61 & 197.77 & 200.75 & 190.71 & $1.59 \%$ & $-3.58 \%$ \\
\hline & weighted price $(\$)$ & 280.14 & 280 & 273 & 298.65 & $-2.55 \%$ & $6.67 \%$ \\
\hline & price $(\$)$ & 239.69 & 239.69 & 238.92 & 260.97 & $-0.32 \%$ & $8.88 \%$ \\
\hline strong-form & revenue $(\$ 1,000)$ & 55.601 & 55.59 & 55.377 & $\mathbf{5 7 . 5 8 5}$ & $-0.40 \%(0.11 \%)$ & $3.59 \%(0.39 \%)$ \\
\hline rational & demand (\# of pax) & 198.41 & 198.48 & 199.03 & 193.18 & $0.31 \%$ & $-2.68 \%$ \\
\hline \multirow[t]{2}{*}{ expectation } & weighted price $(\$)$ & 280.2 & 280.05 & 278.2 & 298.09 & $-0.71 \%$ & $6.45 \%$ \\
\hline & price $(\$)$ & 239.85 & 239.76 & 238.71 & 260.86 & $-0.48 \%$ & $8.80 \%$ \\
\hline
\end{tabular}

Note: Standard deviations are shown in parentheses.

Table 11 Counterfactual Analysis Summarized across All Markets

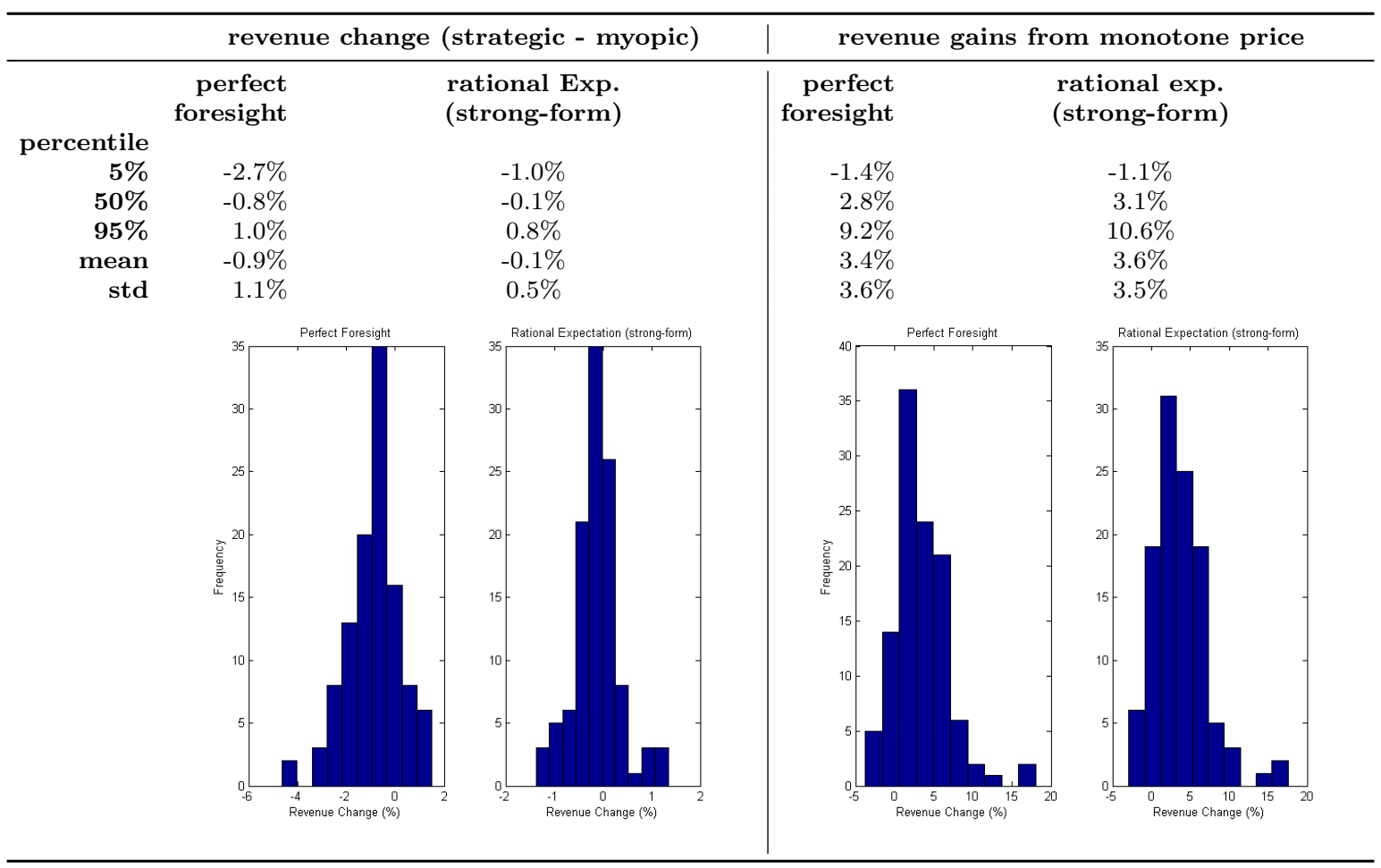




\section{Appendix A: Estimation under Fixed-Effect and Serial Correlation}

To estimate the model with fixed effects and serial correlation in the baseline demand, we apply the following transformation. For simplicity of illustration, in the following discussion we assume a constant fraction of strategic consumers and the same price sensitivity for both non-strategic and strategic consumers. Similar logic can easily be applied to more complicated models. In the demand model, let $X_{m t}$ represent marketdeparture date characteristics $X_{m}$, polynomials of booking time $t$ and the constant

$$
\begin{aligned}
& d_{m t}=\left(1-\theta z_{m t}\right)\left(-\beta p_{m t}+X_{m t} \delta+\varepsilon_{m t}\right)+\theta z_{m, t-1}\left(-\beta p_{m t}+X_{m, t-1} \delta+\varepsilon_{m, t-1}\right) \\
& \varepsilon_{m t}=\mu_{m}+\epsilon_{m t}, \\
& \epsilon_{m t}=\rho \epsilon_{m, t-1}+\nu_{m t} .
\end{aligned}
$$

The demand model can also be written as

$$
\begin{aligned}
& d_{m t}=\hat{d}_{m t}+\left(1-\theta z_{m t}\right) \nu_{m t} \\
& \hat{d}_{m t}=\left(1-\theta z_{m t}\right)\left(-\beta p_{m t}+X_{m t} \delta+\rho \varepsilon_{m, t-1}\right)+\theta z_{m, t-1}\left(-\beta p_{m t}+X_{m, t-1} \delta+\varepsilon_{m, t-1}\right)
\end{aligned}
$$

Note that previously realized demand shock $\varepsilon_{m, t-1}$ can be used to predict demand $\hat{d}_{m t}$ once it is estimated from the previously realized demand $d_{m, t-1}$.

To obtain unbiased estimates through non-linear least square, all we need is the following assumption,

$$
E\left[\left(1-\theta z_{m t}\right) \nu_{m t} \mid X, p\right]=0,
$$

which is satisfied by our assumption that $E\left[\nu_{m t} \mid X, p\right]=0$.

Our goal is to find the parameter set $(\theta, \beta, \rho, \delta)$ that minimizes the sum of squares $\sum\left(d_{m t}-\hat{d}_{m t}\right)^{2}=\sum(1-$ $\left(\theta z_{m t}\right)^{2} \hat{\nu}_{m t}^{2}$, while allowing for possible price endogeneity. Price $p_{m t}$ can be correlated with $\mu_{m}$. Meanwhile, price $p_{m t}$ can also be correlated with $\varepsilon_{m t}$ through correlation with $\varepsilon_{m, t-1}$.

To estimate the model, the general idea is to transform the nonlinear problem to a linear problem - the traditional panel data problem with fixed effect and serial correlation. First, move price to the left-hand side in the demand model, and the right-hand side can be written as the the multiplication of a transformation matrix $Z(\theta)$ and a column vector

$$
\begin{aligned}
d_{m t}+\left(1-\theta z_{m t}+\theta z_{m, t-1}\right) \beta p_{m t} & =\left(1-\theta z_{m t}\right)\left(X_{m t} \delta+\mu_{m}+\epsilon_{m t}\right)+\theta z_{m, t-1}\left(X_{m, t-1} \delta+\mu_{m}+\epsilon_{m, t-1}\right) \\
d+\beta(1-\theta z+\theta \operatorname{lag} z) p & =Z(\theta)(X \delta+\mu+\epsilon) \\
Z^{-1}(\theta)(d+\beta(1-\theta z+\theta \operatorname{lag} z) p) & =X \delta+\mu+\epsilon
\end{aligned}
$$

where lagz is $z$ lagged by one period of time. Let $\tilde{d}_{m t}(\theta, \beta)$ denote the left-hand side. Since

$$
\begin{aligned}
\tilde{d}_{m t}(\theta, \beta) & =X_{m t} \delta+\mu_{m}+\epsilon_{m t}=X_{m t} \delta+\mu_{m}+\rho \epsilon_{m, t-1}+\nu_{m t}, \\
\tilde{d}_{m, t-1}(\theta, \beta) & =X_{m, t-1} \delta+\mu_{m}+\epsilon_{m, t-1} .
\end{aligned}
$$

Take partial difference to remove serial correlation,

$$
\begin{aligned}
\tilde{d}_{m t}(\theta, \beta)-\rho \tilde{d}_{m, t-1}(\theta, \beta) & =\left(X_{m t}-\rho X_{m, t-1}\right) \delta+(1-\rho) \mu_{m}+\nu_{m t} \\
\tilde{\tilde{d}}_{m t}(\theta, \beta, \rho) & =\tilde{X}_{m t}(\rho) \delta+\tilde{\mu}_{m}(\rho)+\nu_{m t} .
\end{aligned}
$$


Now, the problem is transformed to a traditional fixed-effect problem with transformed fixed-effect $\tilde{\mu}_{m}(\rho)$.

$$
\begin{aligned}
\tilde{\tilde{d}}_{m t}(\theta, \beta, \rho)-\overline{\tilde{d}}_{m \cdot}(\theta, \beta, \rho) & =\left(\tilde{X}_{m t}(\rho)-\overline{\tilde{X}}_{m \cdot}(\rho)\right) \delta+\nu_{m t}-\bar{\nu}_{m \cdot}, \\
\dot{d}_{m t}(\theta, \beta, \rho) & =\dot{X}_{m t}(\rho) \delta+\dot{\nu}_{m t},
\end{aligned}
$$

where $\overline{\tilde{\tilde{d}}}_{m}, \overline{\tilde{X}}_{m}$, and $\bar{\nu}$ represent the average of corresponding variables across time $t$.

Now, given any $(\theta, \beta, \rho)$, we are be able to obtain an unbiased estimate of $\delta$ using OLS estimator. The sum of squares, i.e. $\sum\left(1-\theta z_{m t}\right)^{2} \hat{\nu}_{m t}^{2}$, can be calculated as follows,

1. For any given $(\theta, \beta, \rho)$, compute $\dot{d}_{m t}, \dot{X}_{m t}$.

2. Compute the OLS estimator of $\delta$ in Equation 10; denote as $\hat{\delta}$.

3. Compute estimates of residuals in Equation $8, \hat{\tilde{\mu}}_{m}+\hat{\nu}_{m t}=\tilde{\tilde{d}}_{m t}(\theta, \beta, \rho)-\tilde{X}_{m t} \hat{\delta}$.

4. Estimate transformed fixed effect $\hat{\tilde{\mu}}_{m}$ using the average of estimated residuals obtained in step 3 . Calculate $\hat{\nu}_{m t}$ subsequently.

5. Compute sum of squares $(\theta, \beta, \rho)=\sum\left(1-\theta z_{m t}\right)^{2} \hat{\nu}_{m t}^{2}$.

The nonlinear least square procedure is applied to find the optimal $(\theta, \beta, \rho)$ that minimizes sum of squares $(\theta, \beta, \rho)$. One additional comment about the initial observation, since we take partial difference in the model, the degree of freedom decreases by one within each group, i.e., market-departure-date. Simply omitting the first observation is likely to cause inefficiency when the number of groups is small, i.e., 45 departure dates in each market. We apply Prais-Winsten transformation to the first observation in each group, i.e. multiply by the first error term by $\sqrt{1-\rho^{2}}$.

\section{Appendix B: Additional Table}

\begin{tabular}{|c|c|c|c|}
\hline \multicolumn{2}{|c|}{$\begin{array}{l}\text { Weak-Form Rational Exp. } \\
\text { Probit Model } \operatorname{Pr}\left(P_{t}+1<p_{t}\right)\end{array}$} & \multicolumn{2}{|c|}{$\begin{array}{l}\text { Strong-Form Rational Exp. } \\
\text { Supply Model }\end{array}$} \\
\hline current_to_last & $\begin{array}{r}-0.035 \\
(0.732)\end{array}$ & Price $_{t-1}$ & $\begin{array}{r}0.924 \\
(0.033)\end{array}$ \\
\hline current_to_inital & $\begin{array}{r}10.818 \\
(2.819)\end{array}$ & cumulative demand $d_{t-1}$ & $\begin{array}{r}0.046 \\
(0.059)\end{array}$ \\
\hline current_to_mktavg & $\begin{array}{r}-8.257 \\
(2.854)\end{array}$ & & \\
\hline weeklyfare_cv & $\begin{array}{r}-4.167 \\
(1.756)\end{array}$ & & \\
\hline initial price & $\begin{array}{r}0.041 \\
(0.013)\end{array}$ & initial price & $\begin{array}{r}0.043 \\
(0.011)\end{array}$ \\
\hline$t$ & $\begin{array}{r}-0.580 \\
(0.216)\end{array}$ & $t$ & $\begin{array}{r}6.186 \\
(0.055)\end{array}$ \\
\hline$t^{2}$ & $\begin{array}{r}0.127 \\
(0.039)\end{array}$ & $t^{2}$ & $\begin{array}{r}-1.382 \\
(0.946)\end{array}$ \\
\hline$t^{3}$ & $\begin{array}{r}-0.008 \\
(0.002)\end{array}$ & $t^{3}$ & $\begin{array}{r}0.076 \\
(0.045)\end{array}$ \\
\hline & & final week & $\begin{array}{r}31.463 \\
(7.177)\end{array}$ \\
\hline high season & $\begin{array}{r}-1.070 \\
(0.325)\end{array}$ & high season & $\begin{array}{l}10.699 \\
(5.450)\end{array}$ \\
\hline $\begin{array}{r}\text { day-of-week dummies } \\
\text { const }\end{array}$ & $\begin{array}{r}\text { yes } \\
-12.190 \\
(3.381)\end{array}$ & $\begin{array}{r}\text { day-of-week dummies } \\
\text { const }\end{array}$ & $\begin{array}{r}\text { yes } \\
-3.255 \\
(16.176)\end{array}$ \\
\hline pseudo R-square & 0.1729 & R-square & 0.8751 \\
\hline
\end{tabular}

Table 12 Prediction Models for Weak- and Strong-Form Rational Expectations: Market L 


\section{Acknowledgments}

We would like to thank the following people (in the alphabetical order) for comments and suggestions: Gerard Cachon, Karan Girotra, Lorin Hitt, Raghuram Iyengar, Stephen Leider, Benny Mantin, Antonio Moreno, Aviv Nevo, Marcelo Olivares, Nikolay Osadchiy, Sergei Savin, Nicos Savva, Katja Seim, Xuanming Su, Gabriel Weintraub, and conference participants at the Behavioural Operations Conference, the Revenue Management and Pricing Conference, and the MSOM Society Annual Conference. We also thank the corporate sponsor for making data available to us. 